Castillo Díaz Luis (Orcid ID: 0000-0001-9944-9040)

\title{
Advanced hydrogels for treatment of diabetes
}

Juana E. Reyes-Martínez, ${ }^{1}$ Juan A. Ruiz-Pacheco, ${ }^{2}$ Mario A. Flores-Valdéz, ${ }^{3}$ Mohamed A. Elsawy, ${ }^{4}$ Alba A. Vallejo-Cardona, ${ }^{3}$ Luis A. Castillo-Díaz. ${ }^{5 *}$

1. Departamento de Biología. División de Ciencias Naturales y Exactas. Universidad de Guanajuato. Guanajuato, Guanajuato, México.juana.reyes@ugto.mx

2. Centro de Investigación Biomédica de Occidente (CIBO). Guadalajara, Jalisco, México. jaruiz@conacyt.mx

3. Biotecnología Médica y Farmacéutica. Centro de Investigación y Asistencia en Tecnología y Diseño del Estado de Jalisco (CIATEJ). Jalisco, México. floresv@ ciatej.mx, avallejo@ ciatej.mx

4. School of Pharmacy and Biomedical Sciences, University of Central Lancashire, United Kingdom.melsawy@uclan.ac.uk

5. Departamento de Medicina y Ciencias de la Salud. División de Ciencias Biológicas y de la Salud. Universidad de Sonora. Sonora, Hermosillo, México. *Corresponding author: Luis A. Castillo-Díaz. Tel.: (662) 2592121. Ext.\# 4593

\footnotetext{
This article has been accepted for publication and undergone full peer review but has not been through the copyediting, typesetting, pagination and proofreading process which may lead to differences between this version and the Version of Record. Please cite this article as doi: 10.1002/term.2880
} 


\section{Abstract}

Diabetes mellitus is a chronic disease characterized by high levels of glucose in the blood, which leads to metabolic disorders with severe consequences. Today, there is no cure for diabetes. The current management for diabetes and derived medical conditions, such as hyperglycemia, cardiovascular diseases or diabetic foot ulcer, includes life style changes and hypoglycemia based therapy, which do not fully restore euglycemia or the functionality of damaged tissues in patients.

This encourages scientists to work outside their boundaries to develop routes that can potentially tackle such metabolic disorders. In this regard, acellular and cellular approaches have represented an alternative for diabetics, although such treatments still face shortcomings related to limited effectiveness and immunogenicity. The advent of biomaterials has brought significant improvements for such approaches, and three-dimensional extracellular matrix analogous, such as hydrogels, have played a key role in this regard. Advanced hydrogels are being developed to monitor high blood glucose levels and release insulin, as well as serve as a therapeutic technology.

Herein, the state of the art in advanced hydrogels for improving treatment of diabetes, from laboratory technology to commercial products approved by drug safety regulatory authorities, will be concisely summarized and discussed.

Key words. Biomaterials, Biotechnology, Diabetes, Hydrogels, Hyperglycemia, Polymers 


\section{Table of contents}

1. Introduction

2. Biomaterials for treatment of diabetes

3. Glucose-responsive hydrogels to restore euglycemia

4. Naturally-derived hydrogels for cell encapsulation

5. Synthetically-derived hydrogels for cell encapsulation

6. Hydrogels for treatment of diabetes related conditions

6.1 Acellular naturally-derived hydrogels for cardiovascular affections

6.2 Cellular naturally-derived hydrogels for cardiovascular affections.

6.3 Cellular synthetically-derived hydrogels for cardiovascular affections.

6.4 Hydrogel-based bed dressing for DFU application

6.4.1 Angiogenic hydrogel-based bed dressing

6.4.2 Anti-inflammatory hydrogel-based bed dressing

6.4.3 Antimicrobial hydrogel-based bed dressing

6.5 Hydrogels for treatment of nephropathy

6.5.1 Hydrogels for treatment of kidney injury

6.5.2 Hydrogel-based immunotherapy for treatment of nephropathy

6.6 Naturally-derived hydrogels for treatment of neuropathy

6.7 Synthetically-derived hydrogels for treatment of neuropathy

6.8 Hydrogels for treatment of retinopathy

6.8.1 Synthetically-derived hydrogels for treatment of retinopathy

6.8.2 Composite hydrogels for treatment of retinopathy

7. Antidiabetic pharmaceutical products

7.1 Hydrogels as pharmaceutical products for treatment of DM and DMRC

8. Conclusions and future perspectives

9. Acknowledgements

10. Conflict of interest

11. References

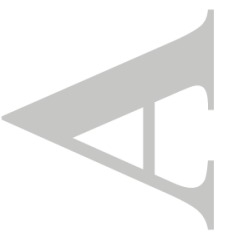

This article is protected by copyright. All rights reserved. 


\section{Introduction}

Diabetes mellitus (DM) is a disease of pandemic proportions with a burden that continues to increase alarmingly throughout the world. In 2015, 1.6 million people worldwide died from DM, making it the 6th ranked cause of death. (Organization, 2017) Diabetes is characterized by chronic hyperglycemia, which is caused by inherited or acquired deficiency in the production of insulin, as well as by the production of defective insulin.

The gold standard for treatment of diabetics relies on diet, life style change and pharmacological therapy. Patients suffering from type I DM (TIDM), follow up the administration of insulin, which is often accompanied by further oral hypoglycemic agents and life style change (obesity management or physical activity). Similarly, patients suffering from type II DM (TIIDM) are subject to medication, usually metformin, which may be accompanied by further oral agents such as glucagon-like peptide-1 (GLP-1) receptor agonist. ("Standards of Medical Care in Diabetes-2017: Summary of Revisions," 2017) When acute glycaemia disorders are developed, patients can undergo islet or whole pancreas transplantation with relatively good prognostic. (Hering et al., 2016; Lebovitz, 2011) Although valuable, this therapy faces limitations related to its high cost, insufficient availability of donors or poor viability of the grafted tissue, which is also linked to lifelong immunotherapy. (Shapiro, Pokrywczynska, \& Ricordi, 2017)

Despite progress in medicine, there is still no cure for hyperglycemia and diabetes mellitus related conditions (DMRC), such as cardiovascular diseases (CVD), diabetic foot ulcer (DFU), among other. In recent years, the advent of biomaterials has broadened the possibilities to improve the current therapeutic strategies focused on treating diabetes. (Neves, Rodrigues, Reis, \& Gomes, 2016) Hydrogels are a class of biomaterials that follow the building-up approach in which, water-soluble monomers form heriarchical structures to give rise more complex polymeric structures. Gels provide a highly moist three-dimensional (3D) network that can be exploited to encapsulate, protect and deliver a myriad of therapeutic compounds, including cells (Figure 1). This makes such materials an appealing toolbox to improve the current strategies that have shown limited success in treating diabetes. (Jabbari, Leijten, Xu, \& Khademhosseini, 2016; Place, Evans, \& Stevens, 2009) Advanced hydrogels are highly versatile since due to their viscoelastic properties they are easy to handle and transfer in a noninvasive manner. Hydrogels are made from either naturally or synthetically-derived polymeric materials, however hybrids of both types of materials are increasingly developed. The latter represents a remarkable advantage in terms of hierarchical, physicochemical and spatial 
organization, which in turns result in significant improvements related to biocompatibility, biological functionality and mechanical stability of hydrogels. (Jabbari et al., 2016)

For treatment of diabetes, hydrogel based antidiabetic strategies seek for optimizing the detection of glucose level imbalances in the blood at the onset of diabetes as well as the release of insulin. For such a purposes, gels must accurately respond to changes in glucose levels, $\mathrm{pH}$ or temperature, from which in situ gelation is critical. (Dong et al., 2016; X. Li et al., 2017; X. Li et al., 2014).

In another application, hydrogels exploiting an acellular approach are designed as therapeutic biologics to accelerate the healing of tissues. (Kasiewicz \& Whitehead, 2017) In this case, drug/growth factors dosages, as well as the shear thinning, self-healing, and self-supporting features of gels are key to allow their therapeutic functions. (Buwalda, Vermonden, \& Hennink, 2017) Lastly, some hydrogels are used as 3D niches to support the culture of a myriad of mature cells as well as to promote the generation of insulin-producing cells from several progenitor cells. For this application, aspects related to cytocompatibility and mechanical stability, are still in laboratory evaluation stages, (Jabbari et al., 2016; Neves et al., 2016) although a few hydrogel-based products are currently commercially available or under clinical evaluation. In this review, the state of the art in advanced hydrogels for improving the treatment of hyperglycemia and DMRC will be concisely discussed, bringing insights on the future of these materials as medical products for treatment of diabetes.

\section{Biomaterials for treatment of diabetes}

Within the most popular class of biomaterials to address the limitations of diabetes therapy include glucose-responsive hydrogels, (Espona-Noguera et al., 2017) sheets, (Shimizu et al., 2009) nanoparticles, (Gu et al., 2013; Szekalska et al., 2017) and glucose-responsive microneedle patches. (Seong et al., 2017; J. Yu et al., 2015) Overall, these materials have been developed to sense glucose, (Shao et al., 2017) deliver insulin and restore euglycemia (Gu et al., 2013; Seong et al., 2017; J. Yu et al., 2015). Other applications include serve as scaffolds for pancreatic tissue engineering applications (Lohmann et al., 2017) and more recently function as vehicles to encapsulate immunogenic agents to generate vaccine candidates to prevent the development of DM (Yoon et al., 2015). Thus, gels formulated from glycan or peptide derived polymers have mechanics and functionality that can be finely tuned to meet the needs of numerous therapeutic applications (Buwalda et al., 2017) 


\section{Glucose-responsive hydrogels to restore euglycemia}

Detecting high glucose rates at the onset of diabetes is a major challenge in the field. Therefore, it is important developing gels having accurate glucose sensitivity that can maintain sustained insulin release. Example of this is an injectable phenylboronic acid-based (PBA) hydrogel, which was developed to monitor high glucose rates once glucose links to deprotected amines of PBA, process that also triggers gelation. Thereafter rhodamine used as a colorimetric indicative can be released in a glucose level-responsive manner, making this gel a potential plataform to generate a glucose detection device in the near future (Dong et al., 2016)

Substituting injection to deliver insulin can avoid painful experience for patients. In this regard, Wang et al. formulated a hydrogel-based microneedle array patch, which consists of polyvinyl alcohol (PVA) linked to $\mathrm{N}^{1}$-(4boronobenzyl)- $\mathrm{N}^{3}$-(4-boronophenyl)- $\mathrm{N}^{1}, \mathrm{~N}^{1}, \mathrm{~N}^{3}, \mathrm{~N}^{3}$ tetramethylpropane-1,3-diaminium (PVA-TSPBA) for the sustained release of insulin through the release of hydrogen peroxide derived from the oxidation of glucose. At physiological $\mathrm{pH}$, the patch displays a fast glucose-dependent insulin release, which extends for up to $20 \mathrm{~h}$. In addition, this patch restored euglycemia once placed on top of the dermis of diabetic mice. (J. Wang et al., 2018)

Likewise, injection of insulin translates into a continuous uncomfortable experience for diabetics. Therefore, reducing administration doses could diminish such an inconvenient. To address this, a vesicular phospholipid gel encapsulating insulin within the hydrogel Pluronic ${ }^{\circ}$ F127 demonstrated to allow safe and continuous release of insulin in vivo for up to 7 days, without leading to inflammatory response. (X. Chen et al., 2018)

Similarly, incorporating PBA-modified porous poly (lactic-co-glycolic acid) (PLGA) microparticles (MPs) (PBA-PLGA MPs) into a hydrogel containing dopamineconjugated hyaluronic acid (HA), it was possible to generate a microparticle hydrogel that dissociates under exposure to hyperglycemic solutions. After this, the hydrogel releases insulin and diabetic mice were able to control blood glucose levels after treatment with the hydrogel for up to 2 weeks, while showing minor inflammation. It was also noted that the hydrogel degraded progresively after 7 weeks. While this is an advantage by avoiding the need for surgical withdrawal, it is clear that subsequent implantations may be required, which in the long run might also compromise the comfort of diabetic patients. (Zhao et al., 2017)

The well-defined amino acid composition makes self-assembled peptide hydrogels (SAPHs), advantageous in terms of reproducibility. Li et al., formulated amphiphilic SAPHs, capable of dissociate in a $\mathrm{pH}$-responsive manner after glucose oxidation. This processes promotes the 
release of insulin to regulate blood glucose levels in vivo. (X. Li et al., 2017) However, control of glucose levels was possible only for up to 6 days, which is shorter compared to PBA-PLGA MPs and far less than the duration of therapeutic effect achieved by transplanting whole islets. Further molecules rather than insulin are also incorporated into gel preparations. For example, three thermosensitive poly ( $\varepsilon$-caprolactone-co-glycolic acid)-poly (ethylene glycol)-poly ( $\varepsilon$ caprolactone-co-glycolic acid) (PCGA-PEG-PCGA) copolymers were synthesized to carry Liraglutide (Lira), which is a derived from the human incretin glucagon like peptide-1 (GLP1). The injection of these formulations was able to regulate blood glucose in vivo, while reducing glycosylated hemoglobin after 3 administrations within 1 month. Because of the outcomes observed, the authors suggest this gel could constitute an option for a weekly treatment of TIIDM patients. (Y. Chen et al., 2016)

Chitosan offers good biocompatibility and biodegradability, for this reason a deoxycholic modified-glycol chitosan hydrogel was designed to electrostatically immobilize and subsequently deliver the GLP-1 antagonist palmityl acylated exendin-4 (Ex-4). Ex-4 release facilitated euglycemia after nasal administration of the chitosan hydrogel into the lungs of diabetic mice by several weeks. (J. Lee et al., 2012) Clinical evaluation of these hydrogel should shed light on the actual feasibility of safely controlling glucose levels in diabetic patients. Furthermore, it seems reasonable to investigate prolonged application in diabetic volunteers. Figure 2 exemplifies some glucose-responsive hydrogel approaches currently avalilabe to restore euglycemia.

\section{Naturally-derived hydrogels for cell encapsulation.}

Today, formulating hydrogels to harbor both pancreatic and progenitor cells to restore euglycemia is one common strategy in the field. Alginate is an anionic polymer, which has been used to encapsulate human cells (L. A. Llacua, Hoek, de Haan, \& de Vos, 2018) and functional moieties, such as collagens type IV and VI, and laminins (Table 1). (A. Llacua, de Haan, Smink, \& de Vos, 2016) Animal pancreatic islets have been used too, despite immunogenicity has been linked to alginate. (de Vos, Faas, Strand, \& Calafiore, 2006)

Modifying alginate gelation parameters has facilitated the insulin secretion of murine INS1E cells, (Espona-Noguera et al., 2018) while human embryonic stem cells (hESCs) cultured inside alginate hydrogels were albe to commit into an endocrine profile after growth factor stimuli. In such cases, that cellular differentiation is stronger under 3D cultures in comparison 
to 2D cultures, (Richardson, Kumta, \& Banerjee, 2014) highlighting the key role of gels as 3D matrices to allow physiological functions of cells.

Combining 3D matrices with bioloectronics is a current approach with promising outcomes in diabetes medicine. Shao and co-workers, formulated an alginate hydrogel, which along with poly-(L-lysine)-alginate beads formed a wireless smartphone-assisted bioelectronics-glucose responsive device. The production of human GLP-1 and murine insulin from genetically engineered cells inside the alginate hydrogel could be remotely triggered through a far-red light (FRL)-responsive optogenetic interface. Additionally, a custom-engineered Bluetooth-active glucometer, facilitated normoglycemia in vivo. (Shao et al., 2017) This elegant engineering approach might represent an advantageous tool to automatically control glycemic levels in diabetics.

By means of using a synthetic nanoporous polymer that is capable of releasing $\mathrm{Ca}^{+2}$, it was possible to boost in situ cross-linking of alginate to form hydrogels, which encapsulated murine islets and once transferred into diabetic mice restored euglycemia over 3 months. In the case of immunodeficient mice transplanted with human islets, the therapeutic effect was prolonged for up to 4 months. This hydrogel could be retrieved from tissue after surgery, which suggests that in the event of failure, malfunction, or exhaustion of cells contained within, it could be possible remove it from a diabetic patient. (An et al., 2018)

Another example includes the transfer of human islets within an alginate hydrogel into immunodeficient diabetic mice, which achieved euglycemia. Thereafter, this formulation was intraperitoneally transferred into a diabetic patient, where it showed to be glucose-responsive over 3 months. However, the grafted islets aggregated in the abdominal wall area of the patient after transfer, (Jacobs-Tulleneers-Thevissen et al., 2013) which encourages further investigations to optimize such an inssue, as well as to rule out any rejection or immunogenicity derived from hydrogel treatment.

The production of insulin is dependent of collagens present in the pancreatic extracellular matrix (ECM). (Kim \& Lee, 2014) This has been shown when porcine islets (McEwan et al., 2016) and murine angiogenic cells (McBane et al., 2013) were cultured within hybrid gels made of collagen and chitosan, respectively. Moreover, the interaction between pancreatic cells and collagens is key to regulate the metabolism of the pancreas and signalling pathways involved in promoting cell survival. (Kim \& Lee, 2014) 
Hyaluronic acid (HA) is a non-sulphated glycosaminoglycan that regulates cell growth and differentiation. In a recent investigation thiolated HA and denatured collagen were cross-linked with polyethylene glycol diacrylate (PEGDA) to form a hydrogel capable of encapsulating canine islet cells and control blood glucose levels in diabetic rats. This hybrid gel was well tolerated at long term as opposed to unencapsulated islets. These promising results must be confirmed in other species, given that host response may differ and lead to reduced half-life or an increased degradation in other subjects. (Harrington, Williams, Rawal, Ramachandran, \& Stehno-Bittel, 2017)

Other hydrogels such as a protein-derived hydrogel (10Q6/5K80) (Beenken-Rothkopf et al., 2013) and Matrigel ${ }^{\circledR}$ have shown to support the differentiation and physiological functions of both human and murine insulin-producing cells under specific stimuli. (Greggio et al., 2013; Lemper et al., 2015; Takeuchi, Nakatsuji, \& Suemori, 2014) However such investigations remain confined to laboratory assays. This is mainly true for Matrigel ${ }^{\circledR}$ due to the nature of source forming it.

\section{Synthetically-derived hydrogels for cell encapsulation.}

Synthetic hydrogels are usually highly reproducible and display little or null immunogenicity (Table 1). (Mehrali et al., 2017) However, sinthetic gels lack of biofunctionality, which can be provided through the incorporation of pancreatic ECM proteins such as, collagen type VI and laminin into synthetic gels to induce pancreatic physiological functions. (L. A. Llacua, Faas, \& de Vos, 2018) A PEG dimethacrylate (PEGDM)-based hydrogel favored the culture of MIN6 murine $\beta$ cells, which after transferred in vivo restored euglycemia over 25 days. (Weber, He, Bradley, Haskins, \& Anseth, 2006) In addition, the encapsulation of whole ECM proteins inside the same gel, improved the function of MIN6 cells over 1 month. This was mainly observed when the highest content of laminin was used. Interestingly, such an insulin production was higher in comparison to PEGDM hydrogels functionalized with lamininderived peptides (Weber \& Anseth, 2008) showing that the short peptide moieties had a limited effect in comparison to the whole proteins. Further investigations should be conducted to shed light on the mechanisms orchestrating the cellular physiological response when either short moieties or whole proteins are used to stimulate cells in gels. 
Similarly, a RGD, IKVAV and GLP-1 functionalized PEG hydrogel was shown to support the survival of murine bone marrow-mesenchymal stem cells (BM-MSCs) and pancreatic islets, where insulin production was enhanced upon glucose and immobilized GLP-1 stimulation. (Bal et al., 2017) The immobilization of GLP-1 and IKVAV within the same hydrogel significantly favored the growth of RINm5F cells. Pancreatic cells inside the hydrogel also were capable of producing insulin, mainly upon glucose stimulation. (Lin \& Anseth, 2009) Even such hydrogels can extend the life span of pancreatic molecules, the short cell culture timing assessed open the question of whether these hydrogels can remain stable under in vivo conditions for extended time, and without raising immunogenic reactions.

In order to promote angiogenesis a PEG-maleimide hydrogel was functionalized with vascular endothelial growth factor (VEGF) and RGD. The hydrogel supported the growth of syngeneic murine islets and promoted angiogenesis in situ after different extrahepatic areas of diabetic mice were explored to assess islets survival. After treatment, normoglycemia could be restored over 1 month in vivo. (Weaver et al., 2017) This PEG hydrogel showed similar effects when transferred into bowel mesentery, which is lesser vascularized than the epididymal fat tissue. (Phelps, Headen, Taylor, Thule, \& Garcia, 2013) Further investigations are necessary to disscard any angiogenic effect derived from the inherent vascularization of the extrahepatic areas explored.

Overall hydrogels usually offer poor stability under physiological conditions. Therefore, blending two polymers having distinctive ductile and rigid properties facilitates the development of stronger hydrogels. (Gong, 2010; Ozawa, Okitsu, \& Takeuchi, 2017) Alginate and polyacrylamide (PAAm) were combined to form a hydrogel that displayed superior mechanics (10-fold tensile strength) than a hydrogel formed only by alginate. The hybrid gel supported the production of insulin by MIN6-m9 cells and once transferred into diabetic mice, the hydrogel restored euglycemia and could be retrieved in a well-structured shape. (Ozawa et al., 2017) However, the hypoglycemic effect that this gel achieved still remains short in comparison to human therapeutic needs.

In this regard, a fully synthetic hydrogel made of poly (N-isopropylacrylamide) (PIPAAm) and PEG, showed the ability to support the proliferation of murine islets and restored normoglycemia at longer time (over 4 months) than the previous alginate/PAAm gel in vivo. (Kodama et al., 2009) 


\section{Hydrogels for treatment of diabetes related conditions}

In the last decades there has been a surge of research in the area of biomaterials to engineering materials that have led to various hydrogel-based systems for the treatment of DM related conditions (DMRC) (Table 2). In this section it will be summarized advanced hydrogels that are following acellular and cellular approaches for such a purpose.

\subsection{Acellular naturally-derived hydrogels for cardiovascular affections}

The development of cardiovascular disease (CVD) is strongly linked to diabetes. Hyperglycemia increases oxidative stress, which leads to vascular complications. Coronary calcifications during diabetes also impairs myocardial function. (Schnell et al., 2013) One principal CVD is myocardial infarction (MI), whose management includes medication (antiinflammatory, anticoagulant and fibrinolytic agents). CVD also may lead to the need of whole heart or synthetic implants transplantation. (Hasan et al., 2015) The low availability of donors, and the limited lifespan of implants makes it necessary to look for alternatives such as the injection of cardiac cells and stem cells. However, this faces restrictions related to immunogenicity, poor cellular retention, and biological activity. (Saludas, Pascual-Gil, Prosper, Garbayo, \& Blanco-Prieto, 2017) Today, MI is being addressed by advanced hydrogels (Table 2). For example, an in situ polymerizable alginate hydrogel injected into a swine-based myocardial infarction model, was shown to be safe, since neither vascular thrombi, ischemia or abnormal cardiac functions were observed. Additionally, the hydrogel favored the migration of myofibroblasts in the treated tissue and showed full degradation within 2 months after transfer. (Leor et al., 2009) In a different MI model (Fisher rats) it was shown that both VEGF and platelet derived growth factor (PDGF) within an alginate hydrogel improved systolic functions and promoted angiogenesis after both were released over 4 weeks of treatment. (Hao et al., 2007)

\subsection{Cellular naturally-derived hydrogels for cardiovascular affections}

Basic research conducted to explore the viability of cardiac cells inside naturally-derived matrices is still ongoing (Table 2), such is the case of murine cardiac cells cultured within Matrigel $^{\circledR}$, which were capable of behave in a physiological-like manner, as they formed cardiac-like fibers. (Bakunts, Gillum, Karabekian, \& Sarvazyan, 2008) Likewise, a collagen hydrogel showed supported the differentiation and contraction of cardiac myofibroblasts, after being stimulated with transforming growth factor-beta (TGF- $\beta$ ). (Lijnen, Petrov, \& Fagard, 
2003) Similarly, a porcine decellularized heart ECM and collagen I-derived hydrogel was shown to support the growth of human cardiac cells, which were capable of beating without further stimulation. (Duan et al., 2011)

In a different investigation, the stiffness and electrical conductivity of a collagen hydrogel were tuned by combining collagen with carbon nanotubes to allow the culture of cardiac cells. The resulting hydrogel was capable of supporting the growth and rhythmical contraction of murine cardiomyocytes. (H. Yu, Zhao, Huang, \& Du, 2017) While such investigations clearly show the suitability of hydrogels to allow physiological functions of cardiac cells, future investigations in vivo are necessary to confirm the feasibility of using such systems under physiological conditions at long term.

In this context, an angiopoietin-1 derived peptide QHREDGS-functionalized chitosan/collagen hydrogel promoted the survival of murine cardiomyocytes in vitro. After subcutaneous transference of the chitosan solution into the back of rats, gelation was induced in situ, which facilitates the retention of the hydrogel in the treated tissue and induced the growth of myofibroblasts and cardiomyocytes after 1 week of being transferred. (Reis et al., 2012)

Biomedical devices must be handy for surgeons, which is a challenge for biomedical engineers. In this context, a fibrin gel has shown to allow the contraction of murine cardiomyocytes upon electrical stimulation under 3D cell culture conditions. (Yuan Ye, Sullivan, \& Black, 2011) Likewise, fibrin was recently used to develop a hydrogel capable of passing throughout catheters for cardiac tissue engineering applications. The hydrogel also was shown to support the culture of human mesenchymal stem cells (hMSCs), which after following intramyocardial delivery in vivo, promoted the retention of hMSCs. (Martens et al., 2009)

Inducing vascularization is a common approach to improve the functionality of myocardium mainly following infarction. Such is the case of another fibrin hydrogel, which supported the migration of murine endothelial progenitor cells in vitro. Thereafter, the hydrogel containing a high density of endothelial cells induced vascularization of ischemic myocardium after grafted in vivo. This treatment also succeeded to reduce myocardial fibrosis after 4 weeks, which resulted in reduction of scarring. (Atluri et al., 2014) As for other hydrogel systems, further investigations are yet necessary to assess the biofunctionality of fibrin gels at clinical stages. 


\subsection{Cellular synthetically-derived hydrogels for cardiovascular affections}

Within synthetic formulations allowing in situ gelation (Table 2), a PEG hydrogel encapsulating erythropoietin (EPO) favored the 3D culture of human induced pluripotent stem cells (iPSCs)-derived cardiomyocytes in vitro. The gelation of PEG solution occurred after it came into contact with the physiological environment and the hydrogel degradation was inversely proportional to the polymer concentration. The injection of the hydrogel containing both iPSCs and EPO into infarcted murine muscle led to the formation of cardiac tissue over 10 weeks of treatment. (Chow et al., 2017)

In addition, a Poly ( $N$-isopropylacrylamide) (PNIPAAm) hydrogel was combined with singlewall carbon nanotubes (SWCNTs) to improve electrical conductivity and promote cellular adhesion. Murine adipose-derived stem cells (ADSCs) proliferated on the surface of the hydrogel. Furthermore, the composite gel promoted cardiac differentiation of ADSCs when transferred into infarcted myocardium in vivo, where cardiac functions improved after 1 month of hydrogel treatment. (X. Li et al., 2014)

The aforementioned investigations put into perspective the suitability of hydrogels for encapsulating cells and biomolecules to improve cardiac tissue functions. Likewise, in situ gelation significantly increases cell viability and retention. However, increasing the use of human cells when hydrogel systems are tested, could shed light on relevant physiological findings that can facilitate the transition of hydrogel-based technologies to the clinic.

\subsection{Hydrogel-based bed dressing for DFU application}

Diabetic foot ulcer is a serious medical complication associated with a high proportion of diabetics. It is estimated that $15 \%$ of them will develop the condition during their lifetime. (Reiber, Lipsky, \& Gibbons, 1998) DFU can be either non-traumatic or can occur following accidental trauma, which commonly happens due to diabetic peripheral neuropathy. The condition is characterized by defective healing derived from ischemia of nerve tissue, which can lead to serious bacterial infections. In late stages, such an infection can turn into limb gangrene that often undergoes surgical amputation. The main strategies for DFU management include wound bed preparation, revascularization and treatment of any infection or chronic inflammation. Therefore, the inherent moist provided by hydrogels to balance hydration along with the incorporation of growth factors makes them highly appealing for DFU treatment (Table 2). (Jeffcoate \& Harding, 2003; Sukumar, Ramachandran, Kalaiarasi, \& Sengottuvelu, 2015) 


\subsubsection{Angiogenic hydrogel-based bed dressing}

In order to induce angiogenesis, a thermosensitive and antioxidant bed dressing called $\mathrm{H}$ HKUST-1, was developed combining poly (PEG citrate) acrylate prepolymer (PPCac) and NIPAM (PPCN hydrogel) (Table 2). This hydrogel encapsulated copper nanoparticles (NPs) (H-HKUST-1 NPs), which have ability to induce angiogenesis. The release of NPs from HHKUST-1 was carried out slowly and at multiple dosages to avoid any non-desired toxicity related to NPs. The H-HKUST-1 hydrogel induced keratinocyte survival and dermal fibroblast migration, without having any cytotoxic effect in vitro, which according to the authors, might be due to the growth factors production derived from the progressive release of copper ions. Wounds in diabetic mice healed over 21 days of treatment with the H-HKUST-1 hydrogel and it was in fact, shown to be significantly less toxic than HKUST-1 NPs alone in solution. In addition, H-HKUST-1 and HKUST-1 NPs promoted the formation of vascular network at the wound site over 32 days, representing an alternative to facilitate the healing of DFU. (Xiao, Chen, Yi, Zhang, \& Ameer, 2017) As in the case with other hydrogels, there is a need of rule out toxicity at long term derived from this copper ions-loaded dressing under physiological conditions.

A self-assembled $N$-acetylglucosamine hydrogel was used to encapsulate polydeoxyribonucleotide (PDRN), which is a linear DNA sequence found in the human placenta. When human embryonic fibroblasts and vascular endothelial cells were cultured in the hydrogel, the expression of angiogenic and antimicrobial markers was induced in vitro. In addition, the re-epithelization and granulation of infected wounds in diabetic mice were accelerated after treatment with the hydrogel. (X. Chen et al., 2016)

Hajimiri et al. designed a human recombinant EGF (rhEGF)-conjugated sodium carboxymethyl chitosan hydrogel to extend the lifespan of rhEGF. This formulation accelerated the closure of wounds in a murine diabetic model within 2 weeks after treatment, results comparable to those under treatment with the commercially available wound dressing Comfeel $^{\circledR}$, which lacks of rHEGF but is capable of absorbing exudate from wounds without adhere. (Hajimiri et al., 2016)

Similarly, a heparin-mimetic amphiphilic peptide (PA) hydrogel effectively accelerated the healing of wounds in vivo. The oligopeptides PALauryl-VVAGEGDK(pbs)S-Am (GAG-PA) and Lauryl-VVAGK-Am (K-PA), interact with each other covalently to form a fibrillar hydrogel having a net negative charge capable to bind VEGF. Moreover, heparan sulphate proteoglycans are known to bind fibroblast growth factor 2 (FGF-2). The heparan signals released from the hydrogel boosted in diabetic mice vascularization, collagen deposition, the 
expression of $\alpha$-SMA, and re-epithelialization after 21 days. Moreover, the hydrogel decreased the production of inflammatory mediators, which according to the authors was key to accelerate the closure of wounds after treatment. (Senturk et al., 2017)

Zhang and co-workers designed a hydrogel formed by chitosan, heparin and poly ( $\gamma$-glutamic acid) $(\gamma$-PGA). In order to scavenge free radicals that are highly produced during chronic inflammation in wounds, the enzyme superoxide dismutase was incorporated into the hydrogel. The positively charged residues of chitosan link the negatively charged heparin and $\gamma$-PGA, which promote angiogenesis. Murine fibroblasts proliferated on the gel and more importantly; the treatment of wounds in diabetic rats with the hydrogel dressing accelerated wound healing, which was accompanied by collagen deposition over 21 days. (Zhang et al., 2018) The capability of this gel to maintain mechanical stability at long term, suggests further exploration in considering this technology for clinical trials.

Another investigation showed that the ADSCs within F127 Pluronic hydrogel differentiated into fibroblastic and endothelial lineages after delivered into diabetic mice dorsal lesions. The treatment with the hydrogel promoted the expression of VEGF and enhanced microvessel density. Wounds treated with the hydrogel accelerated closure, which was accompanied by the formation of granulated tissue, fibroblast proliferation and collagen deposition over 14 days. (Kaisang et al., 2017)

Likewise, the ionic-complemmentary peptide gel RADA-16, supported the culture of murine primary microvascular endothelial cells, which were capable of migrating into the hydrogel. Thereafter, cells formed capillary-like networks and induced the production of VEGF. Moreover, when the hydrogel was transferred into diabetic wounds, their closure was accelerated through the formation of granulated tissue and the production of VEGF after 1 week of treatment. (Cho et al., 2012) According to the authors, a non-specific interaction between cells and the RAD moieties might boost the production of VEGF.

To our knowledge there is a limited number of hydrogels for treatment of DFU being assessed under clinical trials. Recently, an alginate gel loaded with 1 million placenta-derived mesenchymal stem cells (PDMSCs) induced wound healing in a female 57-year old patient presenting with a 20-day DFU. This approach relies on the ability of PDMSCs to produce VEGF, bFGF and EGF involved in wound repair. (Zeng et al., 2017) This watershed investigation is a call to continue testing PDMSCs in a larger population of patients having similar DFU stage affection. 


\subsubsection{Anti-inflammatory hydrogel-based bed dressing}

Moving into an anti-inflammatory approach (Table 2), a glycosaminoglycan (GAG)functionalized PEG hydrogel was designed to covalently capture inflammatory chemokines to accelerate the healing of wounds. This elegant approach relies on the electrostatic interactions between the negatively charged sulphate groups of GAGs and the positively charged residues of chemokines. The heparin hydrogel was shown to effectively bind the monocyte chemoattractant protein-1 (MCP-1) and IL-8. Subsequently, the recruitment of human monocytes and polymorphonuclear cells, was impaired in vitro. Moreover, the healing of wounds in diabetic mice significantly accelerated upon treatment with the GAG-PEG- gel over 10 days. When the hydrogel was transferred into human wound exudates of patients suffering DFU, the expression of inflammatory mediators also decreased significantly with treatment. (Lohmann et al., 2017)

The incorporation of bee venom into a PVA/chitosan hydrogel promoted the healing of chronic wounds in diabetic rats by inducing the production of collagen and decreasing the expression of IL- 6 after topical transfer. The progressive release of bee venom from the gel led to the healing of murine wounds over 21 days of treatment. (Amin \& Abdel-Raheem, 2014)

Chen et al. functionalized a $N$-isopropylacrylamide (NIPAAm) hydrogel with RGD to culture murine BM-MSCs. Such cells are known to have the capability of producing growth factors that aid wound healing. When cultured on RGD-NIPAAm hydrogel, BM-MSCs proliferated and produced transforming growth factor $\beta-1$ (TGF- $\beta 1)$ and basic fibroblast growth factor (bFGF) over 3 days of culture. Once the hydrogel with cells was transferred into chronic wounds in diabetic mice, the closure of wounds was promoted through an anti-inflammatory mechanism, as indicated by a decrease in the population of macrophages over time. In parallel, keratinocytes proliferated and induced granulation in wounds after 1 month of treatment. $(\mathrm{S}$. Chen et al., 2015)

\subsubsection{Antimicrobial hydrogel-based bed dressing}

A hybrid gel made of alginate and agarose has been tested to function as an antimicrobial skin dressing for DFU application (Table 2). This hydrogel is constituted of alginate-based porous sensors loaded with resin beads having a $\mathrm{pH}$-responsive dye, which are embedded within an alginate fiber scaffold loaded with gentamicin. This hydrogel is capable of serving as a 
colorimetric indicator of bacterial infection through detection of changes in $\mathrm{pH}$ values, which can be recorded by a smartphone interface. Alkaline and neutral $\mathrm{pH}$ values were recorded for Pseudomonas aeruginosa and Staphylococcus aureus, respectively. Latter, the gel, efficiently could deliver gentamicin. (Mirani et al., 2017) This approach offers a non-invasive diagnostic and therapeutic alternative for treatment DFU. Furthermore, this skin dressing is made up of FDA approved materials, which represents a significant advantage in terms of biocompatibility that makes it a candidate for clinical trials.

\subsection{Hydrogels for treatment of nephropathy}

Nephropathy represents the major cause of end stage renal disease, and it is strongly linked to DM. (Fineberg, Jandeleit-Dahm, \& Cooper, 2013) Diabetics may also develop chronic kidney disease (CDK), which affects the kidney's structure and function. (Gaitonde, Cook, \& Rivera, 2017) CDK is treated through hemodialysis, peritoneal dialysis or kidney transplantation. However, such therapies have several drawbacks, including risk of infection and death after surgery. Further, kidney grafting faces concerns related to tissue viability and immune rejection. (Sinnakirouchenan \& Holley, 2011)

\subsubsection{Hydrogels for treatment of kidney injury}

Most approaches using advanced hydrogels look for restoring kidney function to mitigate acute kidney injury (AKI) (Table 3). For example, the injection of a murine type I collagen gel into an ischemia reperfusion (IR) renal tissue model in vivo, is capable of inducing the recruitment of renal progenitor stem cells and MSCs. According to the authors this hydrogel might induce the recruitment of stem cells due to the inherent inductive properties of collagen, however it is worth to investigate the role of surrounding cells nearby to ease the recruitment and differentiation of stem cells after hydrogel injection. (S. J. Lee et al., 2018)

Moving to cell-loaded hydrogels, a thermosensitive chitosan chloride hydrogel increased the retention of murine ADSCs implanted in an in vivo IR model to treat AKI. Once injected, the hydrogel reduced the number of ROS-producing cells and renal damage. The hydrogel also showed good rates of degradability and biocompatibility over 14 days of treatment. Further, apoptosis decreased, which correlated to the improved renal function in the animals treated with the hydrogel. (Gao et al., 2012) 


\subsubsection{Hydrogel-based immunotherapy for treatment of nephropathy}

Recently, IL-10 and an anti-TGF- $\beta$ antibody encapsulated within an in situ polymerizable HA hydrogel decreased inflammation and impaired the formation of fibrotic tissue, respectively in murine kidneys (Table 3). A reduction of macrophage infiltration and fibrotic tissue was observed after 25 days of treatment when IL-10 and anti-TGF- $\beta$, respectively, were individually administrated, with the HA hydrogel. Although when both proteins were encapsulated together within the same hydrogel, the animals displayed the formation of fibrotic tissue, which might be due to the induction of alternative TGF- $\beta$-dependent mechanisms of fibrosis. (Rodell, Rai, Faubel, Burdick, \& Soranno, 2015) This study highlights the role of biomolecules as inducers to direct cellular responses when cultured within hydrogels.

Soranno et al., showed that an injectable Dock and Lock (DnL) self-assembly mechanismbased PEG hydrogel also favored the encapsulation and delivery of IL-10 when the injected into the kidneys of mice without inducing any immunogenic reaction. Further, it was shown a reduction of fibrotic tissue upon hydrogel treatment over 35 days, which is longer than previously reported for the HA hydrogel. According to the authors, the aforementioned effects may be due to quenching of the inflammatory process, which may drive the response of antigen-presenting cells through IL-10. (Soranno, Lu, Weber, Rai, \& Burdick, 2014)

Recently chitosan was functionalized with an IGF-1-derived peptide GYGSSSRRAPQT to form a hydrogel capable of promoting the survival and proliferation of ADSCs under 3D cell culture conditions. Further, upon chitosan hydrogel/ADSCs transplantation, macrophage recruitment and TNF- $\alpha$ production decreased in vivo after 3 days. This subsequently favoured an anti-inflammatory effect, which promoted angiogenesis and reduced fibrosis after 2 weeks in vivo. (Feng et al., 2016)

\subsection{Naturally-derived hydrogels for treatment of neuropathy}

During diabetes, sensory, autonomic and motor neuropathies can be developed. Diabetics suffering such neuropathies undergo tight control of glucose levels, which is accompanied by pain reducing drugs or surgical procedures having unsatisfactory outcomes. (Pop-Busui et al., 2017) 
Basic research explores the use of naturally-derived hydrogels to support the culture of various types of cells capable of committing into nerve cells (Table 3). Such is the case of the work led by Valmikinathan et al., who formulated a UV photocrosslinkable chitosan hydrogel, which supported the viability of hMSCs. In addition, the hydrogel promoted the differentiation of murine primary cortical neurons and the formation of neurite extension from murine dorsal root ganglion (DGR) after stimulation with conditioned media. (Valmikinathan et al., 2012)

Likewise, a chitosan/alginate composite hydrogel was suitable to support the growth of murine neural stem cells, as well as olfactory ensheathing cells, which are known to facilitate the recovery of spinal cord injury in vivo. Both types of cells proliferated upon stimulation with neural supplements such as B27 and bFGF after 7 days. (G. Wang, Wang, \& Huang, 2017)

Another approach focuses on tunning the mechanics of silk fibrin (Hopkins et al., 2013), chitosan and alginate gels (Wei, Zhao, Chen, Zhang, \& Zhang, 2016) to match the stiffness of nerve tissue to allow the growth of animal nerve cells. For example, a self-healing hydrogel made of $N$-carboxymethyl chitosan linked to oxidized sodium alginate recorded ca. 80-2000 (Pa) stiffness, which supported the growth of murine neural stem cells mainly when cultured under 3D conditions upon the addition of conditioned media. (Wei et al., 2016)

\subsection{Synthetically-derived hydrogels for treatment of neuropathy}

In an attempt to induce nerve cell migration both short peptide sequences and whole growth factors introduced within hydrogels are the most common strategies used in the field (Table 3). Recently, a RGD-functionalized $\alpha$-helix-based hydrogel that combined two peptide sequences: hSAFp1 and hSAFp2, supported the proliferation and migration of murine embryonic neural stem cells. Moreover, signs of neuronal commitment were evidenced by the expression of the microtubule-associated protein-2 (MAP2), the formation of neurite-like processes and electrophysiological signs. (Mehrban et al., 2015)

Likewise, a functionalized peptide gel called RGD-IKVAV-RADA16 formed from the combination of the oligopeptides RGD-RADA16 (fibronectin moiety) and IKVAV-RADA16 (laminin moiety), induced the growth and migration of nerve cells once the hydrogel was transferred within poly-L-lactic acid (PLLA)-based tubes in a nerve injury model in vivo. Immigrated nerve cells within the peptide gel were capable of bridging a gap through the formation of oriented axons over 4 weeks. (Wu et al., 2017) 
Recently, the F127 Pluronic hydrogel, to which a heparin sulphate was coupled, has been used to encapsulate both bFGF and nerve growth factor (NGF) to induce the regeneration of nerve tissue. Investigations in vitro showed that both bFGF and NGF were progressively released from the Pluronic gel over 35 days. This matched well with the improvements in motor nerve functionality in an injured sciatic nerve model in diabetic rats, which showed significant axon regeneration over 30 days of treatment after a single injection of the hydrogel having both growth factors. (R. Li et al., 2018)

Even though progress has been achieved using hydrogels, the current advances in the field seem to be yet in early stages and future investigations are needed to achieve feasible nerve tissue regeneration in diabetic patients at long-term.

\subsection{Hydrogels for treatment of retinopathy}

Diabetic retinopathy is characterized by swelling and blood leaking from blood vessels nourishing the retina. The subsequent ischemia impairs the integrity of retinal cells. In severe cases, this medical condition often leads to blindness. Medication as well as laser surgery based vitrectomy, are the gold standards used to face retinopathy during diabetes. However, such procedures are highly invasive. The transference of retinal cells to restore ocular function represents a promising alternative for diabetes complaint, however as for other DMRC poor cell viability after grafting remains as an important challenge. (Ola, Nawaz, Khan, \& Alhomida, 2013)

\subsubsection{Synthetically-derived hydrogels for treatment of retinopathy}

To our knowledge a limited number of investigations based in a hydrogel strategy have focused on treating diabetic retinopathy (Table 3). Recently, silicon based hydrogels have been designed to form contact lenses capable of progressively release Epalrestat, which is a drug that inhibits the activity of the enzyme aldose reductase in diabetics. Aldose reductase is known to cause cataract and retinopathy. Silicone hydrogels were capable of maintaining a sustained Epalrestat release over 7 days, while the drug permeated and accumulated in situ, after bovine corneas were treated with hydrogels under hyperglycemic conditions. (Alvarez-Rivera, Concheiro, \& Alvarez-Lorenzo, 2018)

Another investigation explored the capability of an UV photopolymerizable Poly (NIPAAmco-Dex-lactateHEMA) hydrogel made from NIPAAm co Dextran 2-hydroxyethyl methacryl lactate (HEMA-lactate) to extend the delivery of Humalog® (a rapid-acting commercially available insulin). This approach based its feasibility on the slow hydrogel degradation derived 
from outer diffusion of dextran chains after hydrolysis, which allows sustained Humalog® releasing over 5 months in vitro. Interestingly, when the ratio of NIPAAm increased, the insulin release became slower, suggesting that its release is dependent on diffusion and degradation processes of the gel. Insulin released from the hydrogel also favored the expression of cellular survival kinases in murine retinas over 1 month. More significant is the fact that hydrogel treatment decreased apoptosis of retinal cells after a single dose without altering systemic glucose levels. (Imai et al., 2015)

\subsubsection{Hybrid gels for treatment of retinopathy}

Parker and cols., functionalized HA/methylcellulose (MC) with IGF-1, wich has the ability to boost the survival of retinal cells (Table 3). The so-called HAMC hydrogel displayed a MC part that was covalently modified to link either an IGF-1-coupled weak SH3-binding peptide or a IGF-1-coupled strong SH3-binding peptide. From this approach two hydrogels, HAMCWBP and HAMC-SBP, respectively showed steady IGF-1 releasing profiles over 10 days, where the latter exhibited a lower cumulative IGF-1 release in comparison to HAMC-WBP in a hydrogel degradation-independent manner. Further, human retinal epithelium cells cultured within both types of gels showed high viability and displayed a typical neural morphology. (Parker, Mitrousis, \& Shoichet, 2016) Previously, a HAMC hydrogel alone supported the proliferation of murine retinal stem progenitor cells and when this hydrogel was injected into murine sub-retinal tissue, it degraded and left distributed cells throughout the retinal tissue after 4 weeks of treatment. (Ballios, Cooke, van der Kooy, \& Shoichet, 2010) The applications of advanced hydrogels for treatment of DMRC, which include diminishing inflmamatory responses, inducing angiogenesis or promoting physiological functions of local cells to favour the regeneration of affected tissues are summarized in figure 3.

\section{Antidiabetic pharmaceutical products}

Today, there are various membrane-based products (no hydrogels) for hyperglycemia treatment. These antidiabetic devices include DIABECELL ${ }^{\circledR}$, Encaptra $^{\circledR}$ and Sertolin ${ }^{\mathrm{TM}}$, which harbor human and porcine stem cells, which once transferred allow cellular differentiation and insulin production in situ. This technology is currently undergoing clinical trials (phases I and II). (Desai \& Shea, 2017)

As discussed, hydrogels are vehicles used to carry pancreatic cells, hypoclycemiants and insulin, being thixotropic injectable bioadhesive materials that can provide a subcutaneous 
depot of insulin. For those reasons, there has been a lot of interest in developing hydrogelbased formulations for controlled delivery of insulin, (Chaturvedi, Ganguly, Nadagouda, \& Aminabhavi, 2013; Huynh et al., 2008) as well as hydrogel-based cellular scaffolds for tissue regeneration in DFU. (Holmes, Wrobel, Maceachern, \& Boles, 2013; Vyas \& Vasconez, 2014) In the next section, hydrogels for treatment of hyperglycemia and DFU that have been approved by drug safety regulatory authorities and those whose approval is on course will be concisely discussed (Table 4).

\subsection{Hydrogels as pharmaceutical products for treatment of DM and DMRC}

Recent efforts for the development of hydrogel-based formulations for the controlled and responsive release of insulin have been highly confined to research. (Chaturvedi et al., 2013; Gu et al., 2013; Huynh et al., 2008) To our knowledge, there is no hydrogel based insulin formulations approved by drug safety regulatory authorities on the market to date. Recently, Ascendis Pharma has developed the pro-drugs TransCon Hydrogel Insulin, TransCon Hydrogel GLP-1 and a combination of the two, which were sold to Sanofi in 2010 (Table 4). (Ascendis Pharma. TransCon Diabetes Program. Ascendis Pharma Inc [online], 2010; Sanofi, http://www.sanofi.se/l/se/sv/layout. jsp?cnt=9035046E-F46C-4) These products were based on the TransCon technology of Ascendis Pharma, in which insulin and GLP-1 are chemically conjugated to branched PEG through self-cleavable linkers that autohydrolyze under physiological conditions giving sustained release of the active drugs. (Ascendis Pharma. TransCon Diabetes Program. Ascendis Pharma Inc [online], 2010; Sanofi, http://www.sanofi.se/l/se/sv/layout. jsp?cnt=9035046E-F46C-4) TransCon Hydrogel Insulin is currently under phase II clinical trials.

As earlier mentioned DFU is a common DMRC that often carries severe medical consequences. Advances in hydrogel-based platforms have led to the development of therapeutics potentially capable of improving the current DFU management strategies. (Dumville, O'Meara, Deshpande, \& Speak, 2013) Recently, two hydrogel-based cellular skin substitute products have been approved by FDA for the treatment of DFU, Apligraf® and Leucopatch $($ Table 4). Apligraf® is an allogeneic bioengineered skin substitute that is composed of two layers: a lower dermal layer and upper epidermal sheet. The dermal layer is made up of bovine type 1 collagen hydrogel that acts as a 3D scaffold for human fibroblasts. (Bell, Ivarsson, \& Merrill, 1979; Wilkins, Watson, Prosky, Meunier, \& Parenteau, 1994) The collagen acts a hydrating agent and structural protein, which promotes healing per se and by supporting the living fibroblasts, 
which in turn produce other ECM structural proteins, cytokines and growth factors necessary for wound healing. (Wilkins et al., 1994) Despite that the collagenous matrix of Apligraf® supports fibroblast proliferation, the low collagen concentration of the hydrogel $(0.66 \mathrm{mg} / \mathrm{ml})$ showed lower persistence of fibroblasts compared to more concentrated collagen hydrogels (5 $\mathrm{mg} / \mathrm{ml}$ ) over 21 days, as reported by Helary et al. (Helary, Zarka, \& Giraud-Guille, 2012)

Unlike Apligraf ${ }^{\circledR}$, Leucopatch ${ }^{\circledR}$ is an autologous skin substitute product, which is produced using the patient's own venous blood. (Lundquist, Holmstrom, Clausen, Jorgensen, \& Karlsmark, 2013; Reapplix, 2018) The production process does not include the addition of any reagents or excipients and leads to the formation of a triple-layered patch. The external layer is made of a compact polymerized fibrin hydrogel for moisture retention. The middle layer consists of platelets for the release of endogenous wound healing and vascularization growth factors. The bottom layer composed of leucocytes is directly applied onto the wound for protection against bacterial infection. The patch showed high cell recovery for both platelets and leucocytes. High cellular concentrations (ca. 3 billion) induced high levels of growth factors, such as PDGF-AB and VEGF, which correlated to significant antimicrobial activity by leucocytes as shown in the bacterial killing assays against P. aeruginosa. (Lundquist et al., 2013; Reapplix, 2018)

An initial clinical trial showed that Leucopatch ${ }^{\circledR}$ enhanced wound healing in DFU patients. (Jorgensen, Karlsmark, Vogensen, Haase, \& Lundquist, 2011) This was followed by an open multicenter clinical study of 41 patients with hard to heal DFU treated weekly with Leucopatch ${ }^{\circledR}$ that showed 32\% healing within 12 weeks and 54\% within 20 weeks. (Londahl et al., 2015) Currently, a recent randomized controlled clinical trial is running in the UK, Denmark and Sweden on 269 patients with hard to heal DFU with the primary outcome set as percentage of ulcers healed within 20 weeks. (Game et al., 2017) The outcome of this crucial study has yet to be reported. Despite the aforementioned advantages and potential clinical application of Leucopatch ${ }^{\circledR}$ as a DFU treatment product, there are a number of concerns that might jeopardize its accessibility to the wider population of DFU patients. These are mainly the need for highly skilled and trained health care professionals in specialized diabetes foot care clinics/healthcare centers for the on-site production of the patch. Also, a particular Leucopatch ${ }^{\circledR}$ device, which is a centrifuge specifically designed by the supplier for the production of the patch, has to be available on-site for the production process.

Regranex ${ }^{\circledR}$ hydrogel is the only acellular growth factor based hydrogel approved by the FDA as a therapeutic product for DFU. Regranex ${ }^{\circledR}$ is a recombinant PDGF becaplermin in sodium carboxymethylcellulose (NaCMC) hydrogel. The hydrogel base acts as a carrier for 
becaplermin. Becaplermin accelerates wound healing through the chemotactic recruitment of neutrophils and monocytes, thus enhancing the immune response against any possible bacterial infection and stimulating fibroblasts proliferation and collagen type I production. (Fang \& Galiano, 2008) A series of clinical studies have shown statistical significance in accelerated wound healing for experimental groups treated with becaplermin $(0.01 \%)$ in NaCMC hydrogel. This led to the FDA approval of Regranex ${ }^{\circledR}$ hydrogel in 1997 for DFU treatment. (Smiell et al., 1999; Steed, 2006) A recent pharmacovigilance study has revealed an increased rate of mortality secondary to malignancy for patients treated with 3 or more tubes of Regranex ${ }^{\circledR}$ hydrogel, as reported by the supplier. (Smith\&Nephew, 2018) This serious limitation should be considered by healthcare professionals before prescribing Regranex ${ }^{\circledR}$ hydrogel for DFU patients, after a risk-benefit assessment has been done, and should be totally avoided for patients of known malignancy history.

In addition to hydrogel-based dressing such as Hyalogran ${ }^{\circledR}$, SeaSorb®, Fibracol Plus ${ }^{\circledR}$ and Algivon $\AA$ (detailed in Table 4), other acellular hydrogel products such as Purilon $₫$, Intrasite ${ }$, Curasite $\AA$, Dermagride $\AA$, Flaminal Forte $\AA$ and Saf-Gel ${ }^{\circledR}$ have been suggested for DFU treatment but have not yet been approved by regulatory authorities. (Donaghue et al., 1998)

\section{Conclusions and future perspectives}

Today, life expectancy is longer for the whole population, which is in part due to the significant progress that medicine has achieved in recent years. This, in combination with sedentary life styles, poor eating habits, genetics, among other factors, has promoted the development of metabolic syndrome that has affected people worldwide. For this reason, medicine has urged scientists to develop novel strategies that may improve the current therapeutics for treatment of diabetes and DMRC.

There is no doubt that advanced hydrogels as platforms of biological studies, have facilitated the development of devices that potentially can improve the current treatments for DM. However, the transition towards 3D technologies capable of improving the current therapeutics to face DM is still ongoing. From the literature review discussed here, it is evident that most of the biological studies focused in diabetes still exploit animal-based models and cells, which undoubtedly makes the transition to clinical stages harder. Therefore, it is imperative to turn to biological evaluations based as much as possible on the use of human derived biologics that better mirror the human physiology. 
Since biological evaluations are increasingly carried out within 3D extracellular analogous such as hydrogels, it is important considering held such evaluations in situ. This means exploiting such 3D platforms (hydrogels or tissues) at the maximum, since the current disruptive methods (cellular or protein extraction) used, undoubtedly increase the variability and misinterpretation of the findings obtained. This will shorten the pathway to develop more effective routes to potentially tackle DM.

Overall, the progress that advanced hydrogels have achieved as antidiabetic technology still fits early technology readiness and only a few hydrogel-based devices are available as pharmaceutical products for diabetic patients. However, advanced hydrogel based technology in combination with bioelectronics, recombinant biology, bioprinting and pharmaceutical industry, represent a plausible route for the development of antidiabetic alternatives for patients suffering from diabetes.

\section{Acknowledgements}

Authors would like to thank the Science and Technology Council of Mexico (CONACYT)Catedras CONACYT Program, and the University of Guanajuato for funding support. Authors also would like to thank Brian Patrick Walsh, MBA for the diligent proofreading of this review article.

\section{Conflict of Interest}

The authors have declared that there is no conflict of interest with respect the authorship or publication of this review article. 


\section{References}

Alvarez-Rivera, F., Concheiro, A., \& Alvarez-Lorenzo, C. (2018). Epalrestat-loaded silicone hydrogels as contact lenses to address diabetic-eye complications. Eur J Pharm Biopharm, 122, 126-136. doi:10.1016/j.ejpb.2017.10.016

Amin, M. A., \& Abdel-Raheem, I. T. (2014). Accelerated wound healing and antiinflammatory effects of physically cross linked polyvinyl alcohol-chitosan hydrogel containing honey bee venom in diabetic rats. Arch Pharm Res, 37(8), 1016-1031. doi:10.1007/s12272-013-0308-y

An, D., Chiu, A., Flanders, J. A., Song, W., Shou, D., Lu, Y. C., . . Ma, M. (2018). Designing a retrievable and scalable cell encapsulation device for potential treatment of type 1 diabetes. Proc Natl Acad Sci U S A, 115(2), E263-E272. doi:10.1073/pnas.1708806115

Ascendis Pharma. TransCon Diabetes Program. Ascendis Pharma Inc [online], h. a. c. (2010). TransCon Diabetes Program. . http://ascendispharma.com/product-pipeline/transcondiabetes-program/(2010)

Atluri, P., Miller, J. S., Emery, R. J., Hung, G., Trubelja, A., Cohen, J. E., . . Woo, Y. J. (2014). Tissue-engineered, hydrogel-based endothelial progenitor cell therapy robustly revascularizes ischemic myocardium and preserves ventricular function. $J$ Thorac Cardiovasc Surg, 148(3), 1090-1097; discussion 1097-1098. doi:10.1016/j.jtcvs.2014.06.038

Bakunts, K., Gillum, N., Karabekian, Z., \& Sarvazyan, N. (2008). Formation of cardiac fibers in Matrigel matrix. Biotechniques, 44(3), 341-348. doi:10.2144/000112682

Bal, T., Nazli, C., Okcu, A., Duruksu, G., Karaoz, E., \& Kizilel, S. (2017). Mesenchymal stem cells and ligand incorporation in biomimetic poly(ethylene glycol) hydrogels significantly improve insulin secretion from pancreatic islets. J Tissue Eng Regen Med, 11(3), 694-703. doi:10.1002/term.1965

Ballios, B. G., Cooke, M. J., van der Kooy, D., \& Shoichet, M. S. (2010). A hydrogel-based stem cell delivery system to treat retinal degenerative diseases. Biomaterials, 31(9), 2555-2564. doi:10.1016/j.biomaterials.2009.12.004

Beenken-Rothkopf, L. N., Karfeld-Sulzer, L. S., Davis, N. E., Forster, R., Barron, A. E., \& Fontaine, M. J. (2013). The Incorporation of Extracellular Matrix Proteins in Protein Polymer Hydrogels to Improve Encapsulated Beta-cell Function. Annals of Clinical \& Laboratory Science, 43(2), 111-121.

Bell, E., Ivarsson, B., \& Merrill, C. (1979). Production of a tissue-like structure by contraction of collagen lattices by human fibroblasts of different proliferative potential in vitro. Proceedings of the National Academy of Sciences of the United States of America, 76(3), 1274-1278.

Buwalda, S. J., Vermonden, T., \& Hennink, W. E. (2017). Hydrogels for Therapeutic Delivery: Current Developments and Future Directions. Biomacromolecules, 18(2), 316-330. doi:10.1021/acs.biomac.6b01604

Chaturvedi, K., Ganguly, K., Nadagouda, M. N., \& Aminabhavi, T. M. (2013). Polymeric hydrogels for oral insulin delivery. J Control Release, 165(2), 129-138. doi:10.1016/j.jconrel.2012.11.005

Chen, S., Shi, J., Zhang, M., Chen, Y., Wang, X., Zhang, L., . . Zhang, L. (2015). Mesenchymal stem cell-laden anti-inflammatory hydrogel enhances diabetic wound healing. Sci Rep, 5, 18104. doi:10.1038/srep18104

Chen, X., Wong, B. C. K., Chen, H., Zhang, S., Bian, Z., Zhang, G., . . Yang, Z. (2018). Long-lasting Insulin Treatment Via a Single Subcutaneous Administration of Liposomes in Thermoreversible Pluronic(R) F127 Based Hydrogel. Curr Pharm Des, 23(39), 6079-6085. doi:10.2174/1381612823666170509123844 
Chen, X., Zhou, W., Zha, K., Liu, G., Yang, S., Ye, S., . . Cao, F. (2016). Treatment of chronic ulcer in diabetic rats with self assembling nanofiber gel encapsulatedpolydeoxyribonucleotide. American Journal of Translational Research, 8(7), 30673076.

Chen, Y., Luan, J., Shen, W., Lei, K., Yu, L., \& Ding, J. (2016). Injectable and Thermosensitive Hydrogel Containing Liraglutide as a Long-Acting Antidiabetic System. ACS Appl Mater Interfaces, 8(45), 30703-30713. doi:10.1021/acsami.6b09415

Cho, H., Balaji, S., Sheikh, A. Q., Hurley, J. R., Tian, Y. F., Collier, J. H., . . Narmoneva, D. A. (2012). Regulation of endothelial cell activation and angiogenesis by injectable peptide nanofibers. Acta Biomater, 8(1), 154-164. doi:10.1016/j.actbio.2011.08.029

Chow, A., Stuckey, D. J., Kidher, E., Rocco, M., Jabbour, R. J., Mansfield, C. A., . . . Athanasiou, T. (2017). Human Induced Pluripotent Stem Cell-Derived Cardiomyocyte Encapsulating Bioactive Hydrogels Improve Rat Heart Function Post Myocardial Infarction. Stem Cell Reports, 9(5), 1415-1422. doi:10.1016/j.stemcr.2017.09.003

de Vos, P., Faas, M. M., Strand, B., \& Calafiore, R. (2006). Alginate-based microcapsules for immunoisolation of pancreatic islets. Biomaterials, 27(32), 5603-5617. doi:10.1016/j.biomaterials.2006.07.010

Desai, T., \& Shea, L. D. (2017). Advances in islet encapsulation technologies. Nat Rev Drug Discov, 16(5), 338-350. doi:10.1038/nrd.2016.232

Donaghue, V. M., Chrzan, J. S., Rosenblum, B. I., Giurini, J. M., Habershaw, G. M., \& Veves, A. (1998). Evaluation of a collagen-alginate wound dressing in the management of diabetic foot ulcers. Adv Wound Care, 11(3), 114-119.

Dong, Y., Wang, W., Veiseh, O., Appel, E. A., Xue, K., Webber, M. J., . . Anderson, D. G. (2016). Injectable and Glucose-Responsive Hydrogels Based on Boronic AcidGlucose Complexation. Langmuir, 32(34), 8743-8747. doi:10.1021/acs.langmuir.5b04755

Duan, Y., Liu, Z., O'Neill, J., Wan, L. Q., Freytes, D. O., \& Vunjak-Novakovic, G. (2011). Hybrid gel composed of native heart matrix and collagen induces cardiac differentiation of human embryonic stem cells without supplemental growth factors. $J$ Cardiovasc Transl Res, 4(5), 605-615. doi:10.1007/s12265-011-9304-0

Dumville, J. C., O'Meara, S., Deshpande, S., \& Speak, K. (2013). Hydrogel dressings for healing diabetic foot ulcers. Cochrane Database Syst Rev(7), CD009101. doi:10.1002/14651858.CD009101.pub3

Espona-Noguera, A., Ciriza, J., Canibano-Hernandez, A., Fernandez, L., Ochoa, I., Saenz Del Burgo, L., \& Pedraz, J. L. (2017). Tunable injectable alginate-based hydrogel for cell therapy in Type 1 Diabetes Mellitus. Int J Biol Macromol. doi:10.1016/j.ijbiomac.2017.09.103

Espona-Noguera, A., Ciriza, J., Canibano-Hernandez, A., Fernandez, L., Ochoa, I., Saenz Del Burgo, L., \& Pedraz, J. L. (2018). Tunable injectable alginate-based hydrogel for cell therapy in Type 1 Diabetes Mellitus. Int J Biol Macromol, 107(Pt A), 1261-1269. doi:10.1016/j.ijbiomac.2017.09.103

Fang, R. C., \& Galiano, R. D. (2008). A review of becaplermin gel in the treatment of diabetic neuropathic foot ulcers. Biologics : Targets \& Therapy, 2(1), 1-12.

Feng, G., Zhang, J., Li, Y., Nie, Y., Zhu, D., Wang, R., . . Li, Z. (2016). IGF-1 C DomainModified Hydrogel Enhances Cell Therapy for AKI. J Am Soc Nephrol, 27(8), 23572369. doi:10.1681/ASN.2015050578 
Fineberg, D., Jandeleit-Dahm, K. A., \& Cooper, M. E. (2013). Diabetic nephropathy: diagnosis and treatment. Nat Rev Endocrinol, 9(12), 713-723. doi:10.1038/nrendo.2013.184

Gaitonde, D. Y., Cook, D. L., \& Rivera, I. M. (2017). Chronic Kidney Disease: Detection and Evaluation. Am Fam Physician, 96(12), 776-783.

Game, F., Jeffcoate, W., Tarnow, L., Day, F., Fitzsimmons, D., \& Jacobsen, J. (2017). The LeucoPatch(R) system in the management of hard-to-heal diabetic foot ulcers: study protocol for a randomised controlled trial. Trials, 18(1), 469. doi:10.1186/s13063017-2216-9

Gao, J., Liu, R., Wu, J., Liu, Z., Li, J., Zhou, J., . . Wang, C. (2012). The use of chitosan based hydrogel for enhancing the therapeutic benefits of adipose-derived MSCs for acute kidney injury. Biomaterials, 33(14), 3673-3681.

doi:10.1016/j.biomaterials.2012.01.061

Gong, J. P. (2010). Why are double network hydrogels so tough? Soft Matter, 6(12), 25832590. doi:10.1039/B924290B

Greggio, C., De Franceschi, F., Figueiredo-Larsen, M., Gobaa, S., Ranga, A., Semb, H., . . Grapin-Botton, A. (2013). Artificial three-dimensional niches deconstruct pancreas development in vitro. Development, 140(21), 4452-4462. doi:10.1242/dev.096628

Gu, Z., Aimetti, A. A., Wang, Q., Dang, T. T., Zhang, Y., Veiseh, O., . . Anderson, D. G. (2013). Injectable nano-network for glucose-mediated insulin delivery. ACS Nano, 7(5), 4194-4201. doi:10.1021/nn400630x

Hajimiri, M., Shahverdi, S., Esfandiari, M. A., Larijani, B., Atyabi, F., Rajabiani, A., . . Dinarvand, R. (2016). Preparation of hydrogel embedded polymer-growth factor conjugated nanoparticles as a diabetic wound dressing. Drug Dev Ind Pharm, 42(5), 707-719. doi:10.3109/03639045.2015.1075030

Hao, X., Silva, E. A., Mansson-Broberg, A., Grinnemo, K. H., Siddiqui, A. J., Dellgren, G., . . Sylven, C. (2007). Angiogenic effects of sequential release of VEGF-A165 and PDGF-BB with alginate hydrogels after myocardial infarction. Cardiovasc Res, 75(1), 178-185. doi:10.1016/j.cardiores.2007.03.028

Harrington, S., Williams, J., Rawal, S., Ramachandran, K., \& Stehno-Bittel, L. (2017). Hyaluronic Acid/Collagen Hydrogel as an Alternative to Alginate for Long-Term Immunoprotected Islet Transplantation(). Tissue Eng Part A, 23(19-20), 1088-1099. doi:10.1089/ten.TEA.2016.0477

Hasan, A., Khattab, A., Islam, M. A., Hweij, K. A., Zeitouny, J., Waters, R., . . Paul, A. (2015). Injectable Hydrogels for Cardiac Tissue Repair after Myocardial Infarction. Adv Sci (Weinh), 2(11), 1500122. doi:10.1002/advs.201500122

Helary, C., Zarka, M., \& Giraud-Guille, M. M. (2012). Fibroblasts within concentrated collagen hydrogels favour chronic skin wound healing. J Tissue Eng Regen Med, 6(3), 225-237. doi:10.1002/term.420

Hering, B. J., Clarke, W. R., Bridges, N. D., Eggerman, T. L., Alejandro, R., Bellin, M. D., . . . Clinical Islet Transplantation, C. (2016). Phase 3 Trial of Transplantation of Human Islets in Type 1 Diabetes Complicated by Severe Hypoglycemia. Diabetes Care, 39(7), 1230-1240. doi:10.2337/dc15-1988

Holmes, C., Wrobel, J. S., Maceachern, M. P., \& Boles, B. R. (2013). Collagen-based wound dressings for the treatment of diabetes-related foot ulcers: a systematic review. Diabetes Metab Syndr Obes, 6, 17-29. doi:10.2147/DMSO.S36024

Hopkins, A. M., De Laporte, L., Tortelli, F., Spedden, E., Staii, C., Atherton, T. J., . . . Kaplan, D. L. (2013). Silk Hydrogels as Soft Substrates for Neural Tissue Engineering. Advanced Functional Materials, 23(41), 5140-5149. doi:10.1002/adfm.201300435 
Huynh, D. P., Nguyen, M. K., Pi, B. S., Kim, M. S., Chae, S. Y., Lee, K. C., . . Lee, D. S. (2008). Functionalized injectable hydrogels for controlled insulin delivery. Biomaterials, 29(16), 2527-2534. doi:10.1016/j.biomaterials.2008.02.016

Imai, H., Misra, G. P., Wu, L., Janagam, D. R., Gardner, T. W., \& Lowe, T. L. (2015). Subconjunctivally Implanted Hydrogels for Sustained Insulin Release to Reduce Retinal Cell Apoptosis in Diabetic Rats. Invest Ophthalmol Vis Sci, 56(13), 78397846. doi:10.1167/iovs.15-16998

Jabbari, E., Leijten, J., Xu, Q., \& Khademhosseini, A. (2016). The matrix reloaded: the evolution of regenerative hydrogels. Materials Today, 19(4), 190-196. doi:https://doi.org/10.1016/j.mattod.2015.10.005

Jacobs-Tulleneers-Thevissen, D., Chintinne, M., Ling, Z., Gillard, P., Schoonjans, L., Delvaux, G., . . . Beta Cell Therapy Consortium, E.-F. (2013). Sustained function of alginate-encapsulated human islet cell implants in the peritoneal cavity of mice leading to a pilot study in a type 1 diabetic patient. Diabetologia, 56(7), 1605-1614. doi:10.1007/s00125-013-2906-0

Jeffcoate, W. J., \& Harding, K. G. (2003). Diabetic foot ulcers. Lancet, 361(9368), 15451551. doi:10.1016/S0140-6736(03)13169-8

Jorgensen, B., Karlsmark, T., Vogensen, H., Haase, L., \& Lundquist, R. (2011). A pilot study to evaluate the safety and clinical performance of Leucopatch, an autologous, additive-free, platelet-rich fibrin for the treatment of recalcitrant chronic wounds. Int $J$ Low Extrem Wounds, 10(4), 218-223. doi:10.1177/1534734611426755

Kaisang, L., Siyu, W., Lijun, F., Daoyan, P., Xian, C. J., \& Jie, S. (2017). Adipose-derived stem cells seeded in Pluronic F-127 hydrogel promotes diabetic wound healing. $J$ Surg Res, 217, 63-74. doi:10.1016/j.jss.2017.04.032

Kasiewicz, L. N., \& Whitehead, K. A. (2017). Recent advances in biomaterials for the treatment of diabetic foot ulcers. Biomater Sci, 5(10), 1962-1975. doi:10.1039/c7bm00264e

Kim, M. J., \& Lee, D. Y. (2014). Pancreas-like extracellular matrix scaffold for successful pancreatic islet transplantation. Macromolecular Research, 22(6), 575-582. doi:10.1007/s13233-014-2097-7

Kodama, S., Kojima, K., Furuta, S., Chambers, M., Paz, A. C., \& Vacanti, C. A. (2009). Engineering Functional Islets from Cultured Cells. Tissue Engineering Part A, 15(11), 3321-3329. doi:10.1089/ten.tea.2008.0459

Lebovitz, H. E. (2011). Type 2 diabetes mellitus--current therapies and the emergence of surgical options. Nat Rev Endocrinol, 7(7), 408-419. doi:10.1038/nrendo.2011.10

Lee, J., Lee, C., Kim, T. H., Lee, E. S., Shin, B. S., Chi, S. C., . . Youn, Y. S. (2012). Selfassembled glycol chitosan nanogels containing palmityl-acylated exendin-4 peptide as a long-acting anti-diabetic inhalation system. J Control Release, 161(3), 728-734. doi:10.1016/j.jconrel.2012.05.029

Lee, S. J., Wang, H. J., Kim, T. H., Choi, J. S., Kulkarni, G., Jackson, J. D., . . Yoo, J. J. (2018). In Situ Tissue Regeneration of Renal Tissue Induced by Collagen Hydrogel Injection. Stem Cells Transl Med, 7(2), 241-250. doi:10.1002/sctm.16-0361

Lemper, M., Leuckx, G., Heremans, Y., German, M. S., Heimberg, H., Bouwens, L., \& Baeyens, L. (2015). Reprogramming of human pancreatic exocrine cells to beta-like cells. Cell Death Differ, 22(7), 1117-1130. doi:10.1038/cdd.2014.193

Leor, J., Tuvia, S., Guetta, V., Manczur, F., Castel, D., Willenz, U., . . Cohen, S. (2009). Intracoronary injection of in situ forming alginate hydrogel reverses left ventricular remodeling after myocardial infarction in Swine. J Am Coll Cardiol, 54(11), 10141023. doi:10.1016/j.jacc.2009.06.010 
Li, R., Li, Y., Wu, Y., Zhao, Y., Chen, H., Yuan, Y., . . Xiao, J. (2018). Heparin-Poloxamer Thermosensitive Hydrogel Loaded with bFGF and NGF Enhances Peripheral Nerve Regeneration in Diabetic Rats. Biomaterials, 168, 24-37.

doi:10.1016/j.biomaterials.2018.03.044

Li, X., Fu, M., Wu, J., Zhang, C., Deng, X., Dhinakar, A., . . Ge, L. (2017). pH-sensitive peptide hydrogel for glucose-responsive insulin delivery. Acta Biomater, 51, 294-303. doi:10.1016/j.actbio.2017.01.016

Li, X., Zhou, J., Liu, Z., Chen, J., Lu, S., Sun, H., . . Wang, C. (2014). A PNIPAAm-based thermosensitive hydrogel containing SWCNTs for stem cell transplantation in myocardial repair. Biomaterials, 35(22), 5679-5688.

doi:10.1016/j.biomaterials.2014.03.067

Lijnen, P., Petrov, V., \& Fagard, R. (2003). Transforming growth factor-beta 1-mediated collagen gel contraction by cardiac fibroblasts. J Renin Angiotensin Aldosterone Syst, 4(2), 113-118. doi:10.3317/jraas.2003.011

Lin, C. C., \& Anseth, K. S. (2009). Glucagon-like peptide-1 functionalized PEG hydrogels promote survival and function of encapsulated pancreatic beta-cells. Biomacromolecules, 10(9), 2460-2467. doi:10.1021/bm900420f

Llacua, A., de Haan, B. J., Smink, S. A., \& de Vos, P. (2016). Extracellular matrix components supporting human islet function in alginate-based immunoprotective microcapsules for treatment of diabetes. J Biomed Mater Res A, 104(7), 1788-1796. doi:10.1002/jbm.a.35706

Llacua, L. A., Faas, M. M., \& de Vos, P. (2018). Extracellular matrix molecules and their potential contribution to the function of transplanted pancreatic islets. Diabetologia, 61(6), 1261-1272. doi:10.1007/s00125-017-4524-8

Llacua, L. A., Hoek, A., de Haan, B. J., \& de Vos, P. (2018). Collagen type VI interaction improves human islet survival in immunoisolating microcapsules for treatment of diabetes. Islets, 10(2), 60-68. doi:10.1080/19382014.2017.1420449

Lohmann, N., Schirmer, L., Atallah, P., Wandel, E., Ferrer, R. A., Werner, C., . . . Freudenberg, U. (2017). Glycosaminoglycan-based hydrogels capture inflammatory chemokines and rescue defective wound healing in mice. Sci Transl Med, 9(386). doi:10.1126/scitranslmed.aai9044

Londahl, M., Tarnow, L., Karlsmark, T., Lundquist, R., Nielsen, A. M., Michelsen, M., .. . Jorgensen, B. (2015). Use of an autologous leucocyte and platelet-rich fibrin patch on hard-to-heal DFUs: a pilot study. J Wound Care, 24(4), 172-174, 176-178. doi:10.12968/jowc.2015.24.4.172

Lundquist, R., Holmstrom, K., Clausen, C., Jorgensen, B., \& Karlsmark, T. (2013). Characteristics of an autologous leukocyte and platelet-rich fibrin patch intended for the treatment of recalcitrant wounds. Wound Repair Regen, 21(1), 66-76. doi:10.1111/j.1524-475X.2012.00870.x

Martens, T. P., Godier, A. F., Parks, J. J., Wan, L. Q., Koeckert, M. S., Eng, G. M., . . Vunjak-Novakovic, G. (2009). Percutaneous cell delivery into the heart using hydrogels polymerizing in situ. Cell Transplant, 18(3), 297-304. doi: $10.3727 / 096368909788534915$

McBane, J. E., Vulesevic, B., Padavan, D. T., McEwan, K. A., Korbutt, G. S., \& Suuronen, E. J. (2013). Evaluation of a collagen-chitosan hydrogel for potential use as a proangiogenic site for islet transplantation. PLoS One, 8(10), e77538. doi:10.1371/journal.pone.0077538

McEwan, K., Padavan, D. T., Ellis, C., McBane, J. E., Vulesevic, B., Korbutt, G. S., \& Suuronen, E. J. (2016). Collagen-chitosan-laminin hydrogels for the delivery of 
insulin-producing tissue. J Tissue Eng Regen Med, 10(10), E397-E408. doi:10.1002/term.1829

Mehrali, M., Thakur, A., Pennisi, C. P., Talebian, S., Arpanaei, A., Nikkhah, M., \& Dolatshahi-Pirouz, A. (2017). Nanoreinforced Hydrogels for Tissue Engineering: Biomaterials that are Compatible with Load-Bearing and Electroactive Tissues. $A d v$ Mater, 29(8). doi:10.1002/adma.201603612

Mehrban, N., Zhu, B., Tamagnini, F., Young, F. I., Wasmuth, A., Hudson, K. L., . . . Woolfson, D. N. (2015). Functionalized alpha-Helical Peptide Hydrogels for Neural Tissue Engineering. ACS Biomater Sci Eng, 1(6), 431-439. doi:10.1021/acsbiomaterials.5b00051

Mirani, B., Pagan, E., Currie, B., Siddiqui, M. A., Hosseinzadeh, R., Mostafalu, P., . . . Akbari, M. (2017). An Advanced Multifunctional Hydrogel-Based Dressing for Wound Monitoring and Drug Delivery. Adv Healthc Mater, 6(19). doi:10.1002/adhm.201700718

Neves, L. S., Rodrigues, M. T., Reis, R. L., \& Gomes, M. E. (2016). Current approaches and future perspectives on strategies for the development of personalized tissue engineering therapies. Expert Review of Precision Medicine and Drug Development, 1(1), 93-108. doi:10.1080/23808993.2016.1140004

Ola, M. S., Nawaz, M. I., Khan, H. A., \& Alhomida, A. S. (2013). Neurodegeneration and neuroprotection in diabetic retinopathy. Int J Mol Sci, 14(2), 2559-2572. doi:10.3390/ijms 14022559

Organization, W. H. (2017). The top ten causes of death worldwide. Retrieved from http://www.who.int/mediacentre/factsheets/fs310/en/

Ozawa, F., Okitsu, T., \& Takeuchi, S. (2017). Improvement in the Mechanical Properties of Cell-Laden Hydrogel Microfibers Using Interpenetrating Polymer Networks. ACS Biomaterials Science \& Engineering, 3(3), 392-398. doi:10.1021/acsbiomaterials.6b00619

Parker, J., Mitrousis, N., \& Shoichet, M. S. (2016). Hydrogel for Simultaneous Tunable Growth Factor Delivery and Enhanced Viability of Encapsulated Cells in Vitro. Biomacromolecules, 17(2), 476-484. doi:10.1021/acs.biomac.5b01366

Phelps, E. A., Headen, D. M., Taylor, W. R., Thule, P. M., \& Garcia, A. J. (2013). Vasculogenic bio-synthetic hydrogel for enhancement of pancreatic islet engraftment and function in type 1 diabetes. Biomaterials, 34(19), 4602-4611. doi:10.1016/j.biomaterials.2013.03.012

Place, E. S., Evans, N. D., \& Stevens, M. M. (2009). Complexity in biomaterials for tissue engineering. Nat Mater, 8(6), 457-470. doi:10.1038/nmat2441

Pop-Busui, R., Boulton, A. J., Feldman, E. L., Bril, V., Freeman, R., Malik, R. A., . . Ziegler, D. (2017). Diabetic Neuropathy: A Position Statement by the American Diabetes Association. Diabetes Care, 40(1), 136-154. doi:10.2337/dc16-2042

Reapplix. (2018). How 3CPTM Technology produces a Leucopatch. from Reapplix http://www.reapplix.com/product/technology

Reiber, G. E., Lipsky, B. A., \& Gibbons, G. W. (1998). The burden of diabetic foot ulcers. Am J Surg, 176(2A Suppl), 5S-10S.

Reis, L. A., Chiu, L. L., Liang, Y., Hyunh, K., Momen, A., \& Radisic, M. (2012). A peptidemodified chitosan-collagen hydrogel for cardiac cell culture and delivery. Acta Biomater, 8(3), 1022-1036. doi:10.1016/j.actbio.2011.11.030

Richardson, T., Kumta, P. N., \& Banerjee, I. (2014). Alginate encapsulation of human embryonic stem cells to enhance directed differentiation to pancreatic islet-like cells. Tissue Eng Part A, 20(23-24), 3198-3211. doi:10.1089/ten.TEA.2013.0659 
Rodell, C. B., Rai, R., Faubel, S., Burdick, J. A., \& Soranno, D. E. (2015). Local immunotherapy via delivery of interleukin-10 and transforming growth factor beta antagonist for treatment of chronic kidney disease. J Control Release, 206, 131-139. doi:10.1016/j.jconrel.2015.03.025

Saludas, L., Pascual-Gil, S., Prosper, F., Garbayo, E., \& Blanco-Prieto, M. (2017). Hydrogel based approaches for cardiac tissue engineering. Int J Pharm, 523(2), 454-475. doi:10.1016/j.ijpharm.2016.10.061

Sanofi, A. P. (http://www.sanofi.se/l/se/sv/layout. jsp?cnt=9035046E-F46C-4). Sanofiaventis Acquires from Ascendis Pharma Worldwide Rights on Drug-Delivery Technology in Diabetes and Related Disorders [Press release]

Schnell, O., Cappuccio, F., Genovese, S., Standl, E., Valensi, P., \& Ceriello, A. (2013). Type 1 diabetes and cardiovascular disease. Cardiovasc Diabetol, 12, 156. doi:10.1186/1475-2840-12-156

Senturk, B., Demircan, B. M., Ozkan, A. D., Tohumeken, S., Delibasi, T., Guler, M. O., \& Tekinay, A. B. (2017). Diabetic wound regeneration using heparin-mimetic peptide amphiphile gel in db/db mice. Biomater Sci, 5(7), 1293-1303. doi: $10.1039 / \mathrm{c} 7 \mathrm{bm} 00251 \mathrm{c}$

Seong, K. Y., Seo, M. S., Hwang, D. Y., O'Cearbhaill, E. D., Sreenan, S., Karp, J. M., \& Yang, S. Y. (2017). A self-adherent, bullet-shaped microneedle patch for controlled transdermal delivery of insulin. J Control Release. doi:10.1016/j.jconrel.2017.03.041

Shao, J., Xue, S., Yu, G., Yu, Y., Yang, X., Bai, Y., . . Ye, H. (2017). Smartphonecontrolled optogenetically engineered cells enable semiautomatic glucose homeostasis in diabetic mice. Sci Transl Med, 9(387). doi:10.1126/scitranslmed.aal2298

Shapiro, A. M., Pokrywczynska, M., \& Ricordi, C. (2017). Clinical pancreatic islet transplantation. Nat Rev Endocrinol, 13(5), 268-277. doi:10.1038/nrendo.2016.178

Shimizu, H., Ohashi, K., Utoh, R., Ise, K., Gotoh, M., Yamato, M., \& Okano, T. (2009). Bioengineering of a functional sheet of islet cells for the treatment of diabetes mellitus. Biomaterials, 30(30), 5943-5949. doi:10.1016/j.biomaterials.2009.07.042

Sinnakirouchenan, R., \& Holley, J. L. (2011). Peritoneal Dialysis Versus Hemodialysis: Risks, Benefits, and Access Issues. Advances in Chronic Kidney Disease, 18(6), 428432. doi:https://doi.org/10.1053/j.ackd.2011.09.001

Smiell, J. M., Wieman, T. J., Steed, D. L., Perry, B. H., Sampson, A. R., \& Schwab, B. H. (1999). Efficacy and safety of becaplermin (recombinant human platelet-derived growth factor-BB) in patients with nonhealing, lower extremity diabetic ulcers: a combined analysis of four randomized studies. Wound Repair Regen, 7(5), 335-346.

Smith\&Nephew, I. (2018). REGRANEX. A front-line solution to a serious problem. https://regranex.com

Soranno, D. E., Lu, H. D., Weber, H. M., Rai, R., \& Burdick, J. A. (2014). Immunotherapy with injectable hydrogels to treat obstructive nephropathy. J Biomed Mater Res A, 102(7), 2173-2180. doi:10.1002/jbm.a.34902

Standards of Medical Care in Diabetes-2017: Summary of Revisions. (2017). Diabetes Care, 40(Suppl 1), S4-S5. doi:10.2337/dc17-S003

Steed, D. L. (2006). Clinical evaluation of recombinant human platelet-derived growth factor for the treatment of lower extremity ulcers. Plast Reconstr Surg, 117(7 Suppl), 143S149S; discussion 150S-151S. doi:10.1097/01.prs.0000222526.21512.4c

Sukumar, N., Ramachandran, T., Kalaiarasi, H., \& Sengottuvelu, S. (2015). Characterization and in vivo evaluation of silk hydrogel with enhancement of dextrin, rhEGF, and alginate beads for diabetic Wistar Albino wounded rats. The Journal of The Textile Institute, 106(2), 133-140. doi:10.1080/00405000.2014.906100 
Szekalska, M., Sosnowska, K., Zakrzeska, A., Kasacka, I., Lewandowska, A., \& Winnicka, K. (2017). The Influence of Chitosan Cross-linking on the Properties of Alginate Microparticles with Metformin Hydrochloride-In Vitro and In Vivo Evaluation. Molecules, 22(1). doi:10.3390/molecules22010182

Takeuchi, H., Nakatsuji, N., \& Suemori, H. (2014). Endodermal differentiation of human pluripotent stem cells to insulin-producing cells in 3D culture. Sci Rep, 4, 4488. doi: $10.1038 /$ srep04488

Valmikinathan, C. M., Mukhatyar, V. J., Jain, A., Karumbaiah, L., Dasari, M., \& Bellamkonda, R. V. (2012). Photocrosslinkable chitosan based hydrogels for neural tissue engineering. Soft Matter, 8(6), 1964-1976. doi:10.1039/c1sm06629c

Vyas, K. S., \& Vasconez, H. C. (2014). Wound Healing: Biologics, Skin Substitutes, Biomembranes and Scaffolds. Healthcare (Basel), 2(3), 356-400. doi: $10.3390 /$ healthcare 2030356

Wang, G., Wang, X., \& Huang, L. (2017). Feasibility of chitosan-alginate (Chi-Alg) hydrogel used as scaffold for neural tissue engineering: a pilot study in vitro. Biotechnology \& Biotechnological Equipment, 31(4), 766-773. doi:10.1080/13102818.2017.1332493

Wang, J., Ye, Y., Yu, J., Kahkoska, A. R., Zhang, X., Wang, C., . . Gu, Z. (2018). CoreShell Microneedle Gel for Self-Regulated Insulin Delivery. ACS Nano, 12(3), 24662473. doi:10.1021/acsnano.7b08152

Weaver, J. D., Headen, D. M., Aquart, J., Johnson, C. T., Shea, L. D., Shirwan, H., \& Garcia, A. J. (2017). Vasculogenic hydrogel enhances islet survival, engraftment, and function in leading extrahepatic sites. Sci Adv, 3(6), e1700184. doi:10.1126/sciadv.1700184

Weber, L. M., \& Anseth, K. S. (2008). Hydrogel encapsulation environments functionalized with extracellular matrix interactions increase islet insulin secretion. Matrix Biol, 27(8), 667-673. doi:10.1016/j.matbio.2008.08.001

Weber, L. M., He, J., Bradley, B., Haskins, K., \& Anseth, K. S. (2006). PEG-based hydrogels as an in vitro encapsulation platform for testing controlled beta-cell microenvironments. Acta Biomater, 2(1), 1-8. doi:10.1016/j.actbio.2005.10.005

Wei, Z., Zhao, J., Chen, Y. M., Zhang, P., \& Zhang, Q. (2016). Self-healing polysaccharidebased hydrogels as injectable carriers for neural stem cells. Sci Rep, 6, 37841. doi:10.1038/srep37841

Wilkins, L. M., Watson, S. R., Prosky, S. J., Meunier, S. F., \& Parenteau, N. L. (1994). Development of a bilayered living skin construct for clinical applications. Biotechnol Bioeng, 43(8), 747-756. doi:10.1002/bit.260430809

Wu, X., He, L., Li, W., Li, H., Wong, W. M., Ramakrishna, S., \& Wu, W. (2017). Functional self-assembling peptide nanofiber hydrogel for peripheral nerve regeneration. Regen Biomater, 4(1), 21-30. doi:10.1093/rb/rbw034

Xiao, J., Chen, S., Yi, J., Zhang, H., \& Ameer, G. A. (2017). A Cooperative Copper MetalOrganic Framework-Hydrogel System Improves Wound Healing in Diabetes. Advanced Functional Materials, 27(1). doi:10.1002/adfm.201604872

Yoon, Y. M., Lewis, J. S., Carstens, M. R., Campbell-Thompson, M., Wasserfall, C. H., Atkinson, M. A., \& Keselowsky, B. G. (2015). A combination hydrogel microparticle-based vaccine prevents type 1 diabetes in non-obese diabetic mice. Sci Rep, 5, 13155. doi:10.1038/srep13155

Yu, H., Zhao, H., Huang, C., \& Du, Y. (2017). Mechanically and Electrically Enhanced CNT-Collagen Hydrogels As Potential Scaffolds for Engineered Cardiac Constructs. ACS Biomaterials Science \& Engineering, 3(11), 3017-3021. doi:10.1021/acsbiomaterials.6b00620 
Yu, J., Zhang, Y., Ye, Y., DiSanto, R., Sun, W., Ranson, D., .. . Gu, Z. (2015). Microneedlearray patches loaded with hypoxia-sensitive vesicles provide fast glucose-responsive insulin delivery. Proc Natl Acad Sci U S A, 112(27), 8260-8265. doi:10.1073/pnas.1505405112

Yuan Ye, K., Sullivan, K. E., \& Black, L. D. (2011). Encapsulation of cardiomyocytes in a fibrin hydrogel for cardiac tissue engineering. J Vis $\operatorname{Exp}(55)$. doi:10.3791/3251

Zeng, X., Tang, Y., Hu, K., Jiao, W., Ying, L., Zhu, L., . . Xu, J. (2017). Three-week topical treatment with placenta-derived mesenchymal stem cells hydrogel in a patient with diabetic foot ulcer: A case report. Medicine (Baltimore), 96(51), e9212. doi:10.1097/MD.0000000000009212

Zhang, L., Ma, Y., Pan, X., Chen, S., Zhuang, H., \& Wang, S. (2018). A composite hydrogel of chitosan/heparin/poly (gamma-glutamic acid) loaded with superoxide dismutase for wound healing. Carbohydr Polym, 180, 168-174. doi:10.1016/j.carbpol.2017.10.036

Zhao, F., Wu, D., Yao, D., Guo, R., Wang, W., Dong, A., . . Zhang, J. (2017). An injectable particle-hydrogel hybrid system for glucose-regulatory insulin delivery. Acta Biomater, 64, 334-345. doi:10.1016/j.actbio.2017.09.044
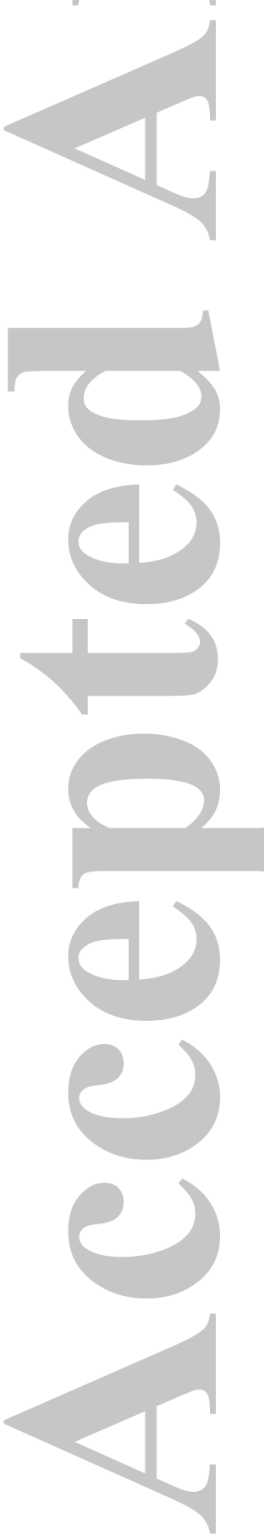

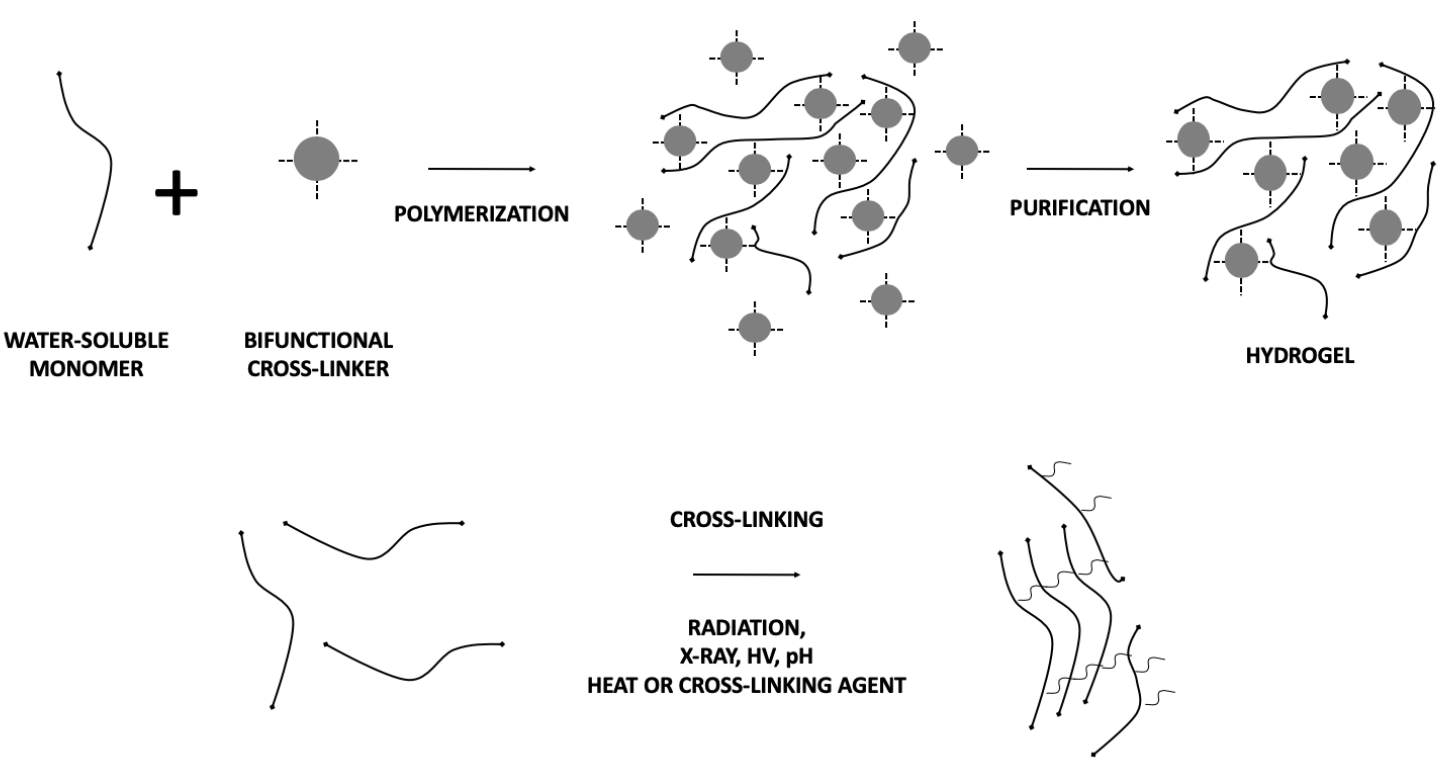

WATER-SOLUBLE POLYMER IN SOLUTION OR IN SOLID STATE

HYDROGEL

Figure 1. Schematic representation of the hierarchical polymerization forming advanced hydrogels. Monomers form more complex structures, which interact with each other through physical or chemical approaches to ultimately form self-supported hydrogels.

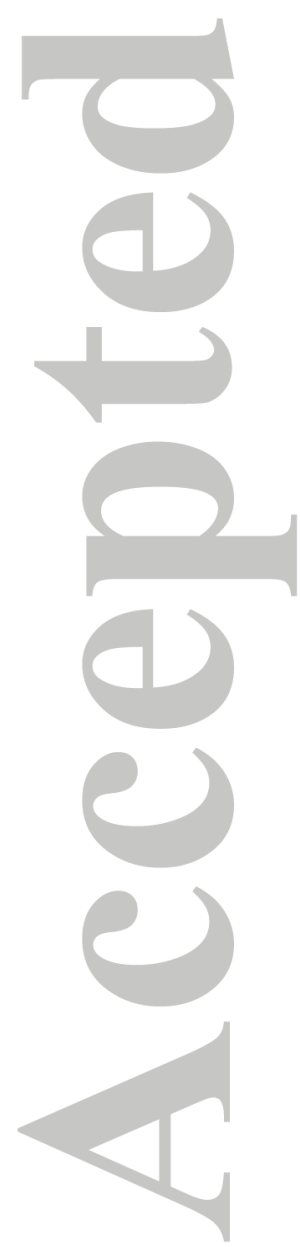



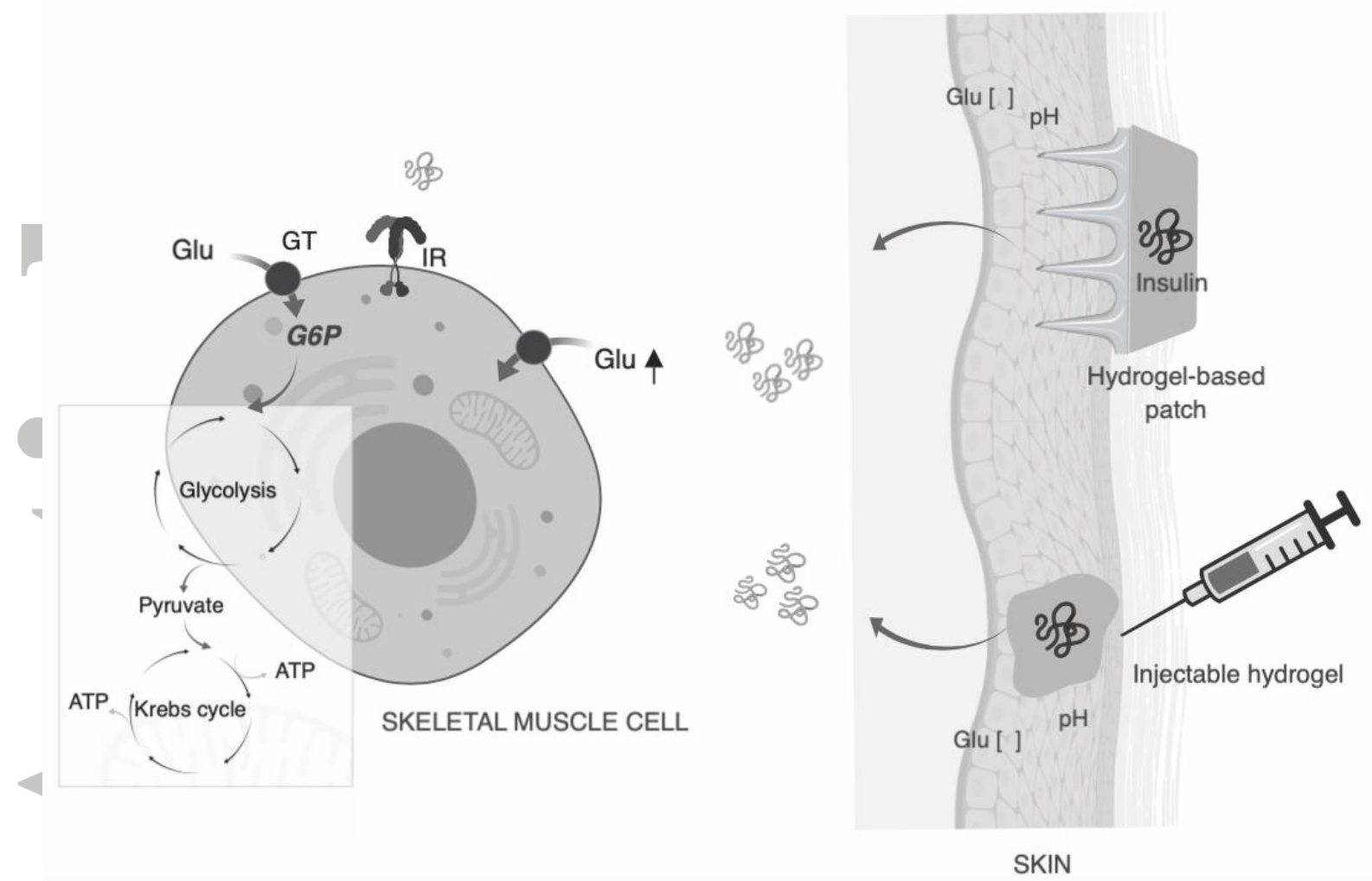

Figure 2. Schematic representation of glucose-responsive hydrogels to restore euglycemia. Both hydrogelbased micro-patch and injectable gels deliver insulin in the long term in a glucose-concentration manner under specific $\mathrm{pH}$ conditions. Glu $=$ Glucose, $\mathrm{GT}=$ Glucose transporter, IR = Insulin receptor. 
A)
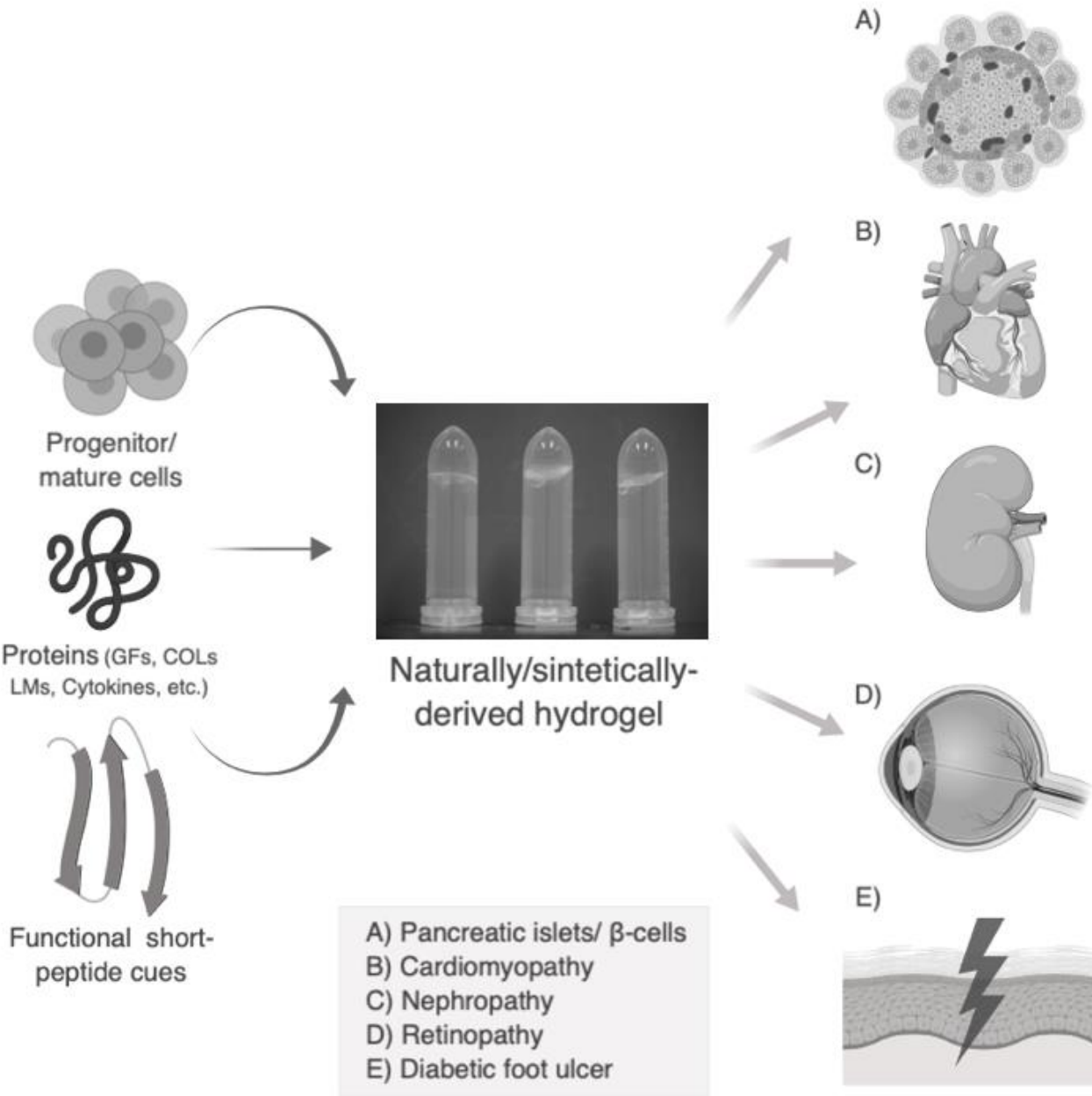

B)
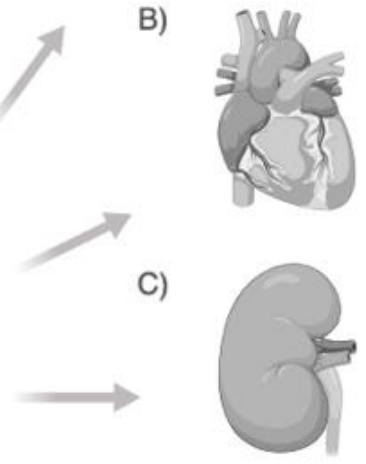

Proteins (GFs, COLs LMs, Cytokines, etc.)
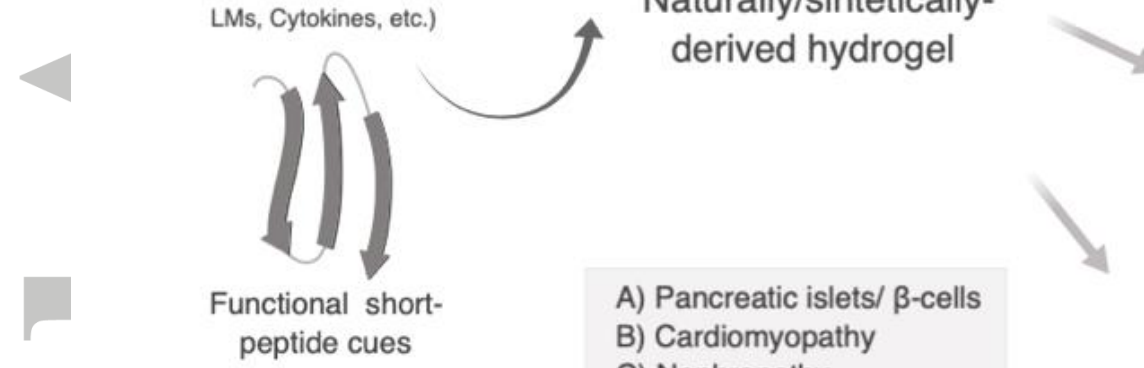

D)

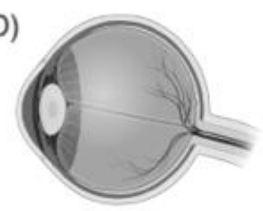

E)

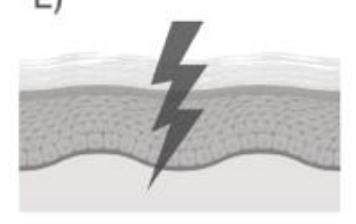

Figure 3. Schematic representation of various hydrogel applications for treatment of DM and DMRC. A) Hydrogels act as a vehicle of a myriad of cells and bioactive molecules to foster insulin production within islets, B) to tackle cardiac failure, C) kidney injury, D) retinopathy or E) DFU once transferred. COLs = collagens, GFs = growth factors, LMs = laminins. 
Table 1. Hydrogels for cell encapsulation.

\begin{tabular}{|c|c|}
\hline \multicolumn{2}{|l|}{ Class } \\
\hline \multirow[b]{5}{*}{$\begin{array}{l}\text { Naturally-derived } \\
\text { hydrogels }\end{array}$} & $\begin{array}{l}\text { Alginate hydrogels harboring whole collagen type VI and functional ECM proteins- } \\
\text { derived moieties, to support the 3D encapsulation of human islets. }\end{array}$ \\
\hline & $\begin{array}{l}\text { Alginate hydrogel with tuned gelation properties for the culture of INS1E cells } \\
\text { (pancreatic cells) and insulin production in vitro. }\end{array}$ \\
\hline & $\begin{array}{l}\text { Alginate hydrogel for the encapsulation and endocrine differentiation of human ESCs } \\
\text { under stimuli with conditioned media in vitro. }\end{array}$ \\
\hline & $\begin{array}{l}\text { Alginate hydrogel } \mathrm{Ca}^{+2} \text {-dependent polymerization for the encapsulation of murine and } \\
\text { human islets to restore euglycemia in vivo. }\end{array}$ \\
\hline & $\begin{array}{l}\text { Alginate hydrogel for 3D culture of human islets to restore euglycemia in vivo and } \\
\text { supporting the activity of } \beta \text {-cells in clinical a trial. }\end{array}$ \\
\hline & $\begin{array}{l}\text { Collagen/chitosan hydrogel with tunable gelation and mechanics for culture of human } \\
\text { angiogenic cells and porcine islets to induce insulin production. }\end{array}$ \\
\hline & $\begin{array}{l}\text { HA/denatured collagen hydrogel cross-linked with PEGDA for encapsulation of canine } \\
\text { islets and restoration of normoglicemia in vivo. }\end{array}$ \\
\hline & $\begin{array}{l}\text { Protein (Q-30/K6) hydrogel to induce the differentiation of MIN6 } \beta \text { cells stimulated with } \\
\text { whole proteins under 3D cell culture conditions. }\end{array}$ \\
\hline & $\begin{array}{l}\text { Matrigel }{ }^{\circledR} \text { to promote the differentiation of hESCs and murine pancreatic progenitor cells } \\
\text { into insulin-producing cells under specific stimuli. }\end{array}$ \\
\hline \multirow{8}{*}{$\begin{array}{l}\text { Synthetically- } \\
\text { derived hydrogels }\end{array}$} & $\begin{array}{l}\text { PEGDM based-hydrogel combined with ECM proteins, as well as functionalized with } \\
\text { laminin-derived moieties to induce the production of insulin by murine islets and restore } \\
\text { euglycemia in vivo. }\end{array}$ \\
\hline & $\begin{array}{l}\text { PEG hydrogel functionalized with laminin derived moieties and GLP-1 to culture murine } \\
\text { BM-MSCs and islets, as well as to induce insulin production. }\end{array}$ \\
\hline & $\begin{array}{l}\text { Photopolymerisable PEG hydrogel functionalized with GLP-1 and IKVAV to support } \\
\text { the production of insulin by RINm5F cells. }\end{array}$ \\
\hline & $\begin{array}{l}\text { PEG hydrogel functionalized with RGD and VEGF for the encapsulation of murine islets } \\
\text { and its transference into small bowel mesentery and epididymal fat tissues of diabetic } \\
\text { mice to induce vascularization and restore normoglicemia. }\end{array}$ \\
\hline & $\begin{array}{l}\text { PAAm DN hydrogel/alginate with stiff mechanics for the differentiation of MIN6m9 } \\
\text { cells and restore normoglicemia in vivo. }\end{array}$ \\
\hline & $\begin{array}{l}\text { PNIPAAm-PEG hydrogel for 3D culture of murine spheroidal islets to promote } \\
\text { euglycemia in diabetic mice. }\end{array}$ \\
\hline & $\begin{array}{l}\text { Alginate/PAAm DN hydrogel to induce the differentiation of MIN6m9 cells and restore } \\
\text { normoglycemia in vivo. }\end{array}$ \\
\hline & $\begin{array}{l}\text { PNIPAAm-PEG hydrogel to culture murine islets to promote euglycemia in diabetic } \\
\text { mice. }\end{array}$ \\
\hline
\end{tabular}

Summary of hydrogels to encapsulate cells.

BM-MSCs = bone marrow-mesenchymal stem cells, $\mathrm{DN}=$ double network, $\mathrm{ECM}=$ extracellular matrix, $\mathrm{ESC}=$ embryonic stem cells, GLP-1 = glucagon-like peptide-1, aspartic acid, respectively, HA = hyaluronic acid, IKVAV = isoleucine, lysine, valine, alanine respectively, PAAm = polyacrylamide, $\mathrm{PEG}=$ polyethylene glycol, PEGDA = polyethylene glycol diacrylate, PEGDM $=$ polyethylene glycol dimethacrylate, PNIPAAm $=$ poly $(N-$ isopropylacrylamide), RGD = arginine, glutamine, aspartica acid respectively, VEGF $=$ vascular endothelial growth factor, $3 \mathrm{D}=$ three-dimensional. 
Table 2. Advanced hydrogels to address myocardial infarction and diabetic foot ulcer.

\begin{tabular}{|c|c|c|}
\hline $\begin{array}{l}\text { Medical } \\
\text { condition }\end{array}$ & Class & Composition and mechanism of action \\
\hline \multirow{9}{*}{$\begin{array}{l}\text { Cardiovascular } \\
\text { affections }\end{array}$} & \multirow[b]{2}{*}{$\begin{array}{l}\text { Acellular naturally- } \\
\text { derived hydrogels }\end{array}$} & In situ polymerizable alginate gel to prevent myocardial elongation and promotes myofibroblast activity in vivo. \\
\hline & & $\begin{array}{l}\text { Alginate hydrogel for the 3D encapsulation and release of VEGF and PDGF to induce angiogenesis and improve cardiac } \\
\text { functions in vivo. }\end{array}$ \\
\hline & \multirow{8}{*}{$\begin{array}{l}\text { Cellular naturally- } \\
\text { derived hydrogels }\end{array}$} & Matrigel $@$ as 3D matrix for culture of murine cardiac cells capable of forming cardiac-like fibers. \\
\hline & & Collagen hydrogels for culture of heart myofibroblasts capable of beating after stimulation with TGF- $\beta$. \\
\hline & & Porcine ECM decellularised/collagen hydrogel to promote the differentiation of contractile cardiac cells. \\
\hline & & $\begin{array}{l}\text { Collagen hydrogel combined with carbon nanotubes to improve gel mechanics and promote rhythmical contraction of murine } \\
\text { neonatal cardiomyocytes. }\end{array}$ \\
\hline & & Fibrin hydrogel for the culture of murine neonatal cardiomyocytes capable of contract under electrical stimuli. \\
\hline & & $\begin{array}{l}\text { Fibrin hydrogel for the 3D culture of human mesenchymal stem cells and favoring their retention when transferred into } \\
\text { myocardium in vivo. }\end{array}$ \\
\hline & & $\begin{array}{l}\text { Fibrin hydrogel for the 3D culture of murine endothelial progenitor cells to promote vascularization and cardiac functions of } \\
\text { ischemic myocardium in vivo. }\end{array}$ \\
\hline & & $\begin{array}{l}\text { Chitosan/collagen hydrogel functionalized with angiopoietin-1 peptide to induce the growth of myofibroblasts and } \\
\text { cardiomyocytes in vivo. }\end{array}$ \\
\hline & \multirow{2}{*}{$\begin{array}{c}\text { Cellular } \\
\text { synthetically- } \\
\text { derived hydrogels }\end{array}$} & $\begin{array}{l}\text { PEG hydrogel designed for in situ gelation and encapsulation of human iPSCs derived cardiomyocytes and EPO to promote } \\
\text { the formation of cardiac tissue in an infarcted model in vivo. }\end{array}$ \\
\hline & & $\begin{array}{l}\text { PNIPAAm hydrogel having carbon nanotubes for the culture of murine cardiac cells and improve their function through } \\
\text { enhanced electrical conductivity in vivo. }\end{array}$ \\
\hline \multirow{10}{*}{$\begin{array}{l}\text { Diabetic foot } \\
\text { ulcer }\end{array}$} & \multirow{9}{*}{$\begin{array}{c}\text { Angiogenic } \\
\text { hydrogel-based bed } \\
\text { dressing }\end{array}$} & $\begin{array}{l}\text { Silk fibroin hydrogel for encapsulation of rhEGF-conjugated chitosan/alginate beads to slowly release rhEGF and promote } \\
\text { wound healing of diabetic rats. }\end{array}$ \\
\hline & & H-HKUST-1 hydrogel to induce angiogenesis and wound healing in vivo through the release of copper ions at long term. \\
\hline & & PDRN hydrogel to promote the healing of diabetic wounds in vivo. \\
\hline & & Chitosan hydrogel for immobilization and protection of rhEGF to accelerate wound healing in vivo. \\
\hline & & $\begin{array}{l}\text { Heparan-mimetic amphiphilic peptide hydrogel to induce wound healing in diabetic mice by promoting angiogenesis, tissue } \\
\text { granulation and decreasing the expression of anti-inflammatory mediators. }\end{array}$ \\
\hline & & $\begin{array}{l}\text { Chitosan, heparin and poly ( } \gamma \text {-glutamic acid) hydrogel having superoxide dismutase to scavenge free radicals and favor wound } \\
\text { healing in vivo. }\end{array}$ \\
\hline & & F127 Pluronic hydrogel for the encapsulation of murine ADSCs to induce angiogenesis and wound closure in vivo. \\
\hline & & RADA16 peptide hydrogel to promote the migration of murine endothelial cells in vitro and induce wound healing in vivo. \\
\hline & & $\begin{array}{l}\text { Alginate/placenta-derived MSCs gel to induce wound healing through stimulating the production of angiogenic growth factors } \\
\text { in a patient presenting } 20 \text {-day DFU. }\end{array}$ \\
\hline & & $\begin{array}{l}\text { Heparan-functionalized PEG hydrogel to scavenge inflammatory chemokines present in DFU and impairing inflammatory } \\
\text { immune cells migration in vitro, in situ and in vivo. }\end{array}$ \\
\hline
\end{tabular}

This article is protected by copyright. All rights reserved. 


\begin{tabular}{|c|c|l|}
\hline & $\begin{array}{c}\text { Anti-inflammatory } \\
\text { hydrogel-based bed } \\
\text { dressing }\end{array}$ & $\begin{array}{l}\text { PVA/chitosan hydrogel harboring bee venom to promote wound healing in diabetic rats through inducing collagen deposition } \\
\text { and decreasing the production of inflammatory IL-6. } \\
\text { RGD-functionalized NIPAAm hydrogel to support culture of murine BM-MSCs and promote wound healing in vivo through } \\
\text { the induction of TGF- } \beta 1 \text { and bFGF. }\end{array}$ \\
\cline { 2 - 3 } & $\begin{array}{c}\text { Antimicrobial } \\
\text { hydrogel-based bed } \\
\text { dressing }\end{array}$ & $\begin{array}{l}\text { Alginate/agarose pH responsive hydrogel as a non-invasive colorimetric indicator of infection and an antimicrobial releasing } \\
\text { device in DFU in vivo. }\end{array}$ \\
\hline
\end{tabular}

Summary of advanced hydrogels to address myocardial infarction and diabetic foot ulcer.

ADSCs = adipose tissue-derived stem cells, BM-MSCs = bone marrow-mesenchymal stem cells, bFGF = basic fibroblast growth factor, DFU = diabetic foot ulcer, ECM = extracellular matrix, EPO = erythropoietin, IL-6 = Interleukin 6, iPSCs = induced pluripotent stem cells, MSCs = human mesenchymal stem cells, NIPAAm = Nisopropylacrylamide, $\mathrm{PEG}=$ polyethylene glycol, $\mathrm{PDGF}=$ platelet-derived growth factor, $\mathrm{PDRN}=N$-acetylglucosamine/polydeoxyribonucleotide, $\mathrm{PNIPAAm}=$ poly $(N$ isopropylacrylamide), PVA = polyvinyl alcohol, RADA = arginine, alanine, aspartic acid, alanine, respectively, RGD = arginine, glutamine, aspartica acid respectively, VEGF $=$ vascular endothelial growth factor, rhEGF $=$ human recombinant epidermal growth factor, TGF- $\beta 1=$ transforming growth factor-beta $1,3 \mathrm{D}=$ three-dimensional.

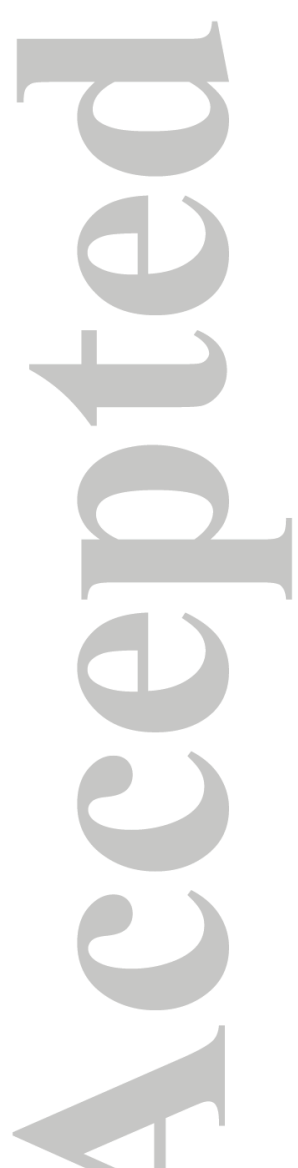


Table 3. Advanced hydrogels to address nephropathy, neuropathy and retinopathy.

\begin{tabular}{|c|c|c|}
\hline $\begin{array}{c}\text { Medical } \\
\text { condition }\end{array}$ & Class & Composition and mechanism of action \\
\hline \multirow{5}{*}{ Nephropathy } & \multirow{2}{*}{$\begin{array}{l}\text { Hydrogels for } \\
\text { treatment of } \\
\text { kidney injury }\end{array}$} & $\begin{array}{l}\text { Collagen hydrogel to induce the recruitment and retention of renal progenitor cells in a murine ischemia reperfusion renal model } \\
\text { in vivo. }\end{array}$ \\
\hline & & $\begin{array}{l}\text { Chitosan hydrogel functionalized with a IGF-1-derived peptide to culture ADSCs, decreasing inflammation and promoting } \\
\text { angiogenesis in renal tissue in vivo. }\end{array}$ \\
\hline & \multirow{3}{*}{$\begin{array}{l}\text { Hydrogel-based } \\
\text { immunotherapy }\end{array}$} & $\begin{array}{l}\text { HA hydrogel to immobilise and deliver IL-10 and anti-TGF- } \beta \text { for treatment of chronic kidney damage through decreasing } \\
\text { inflammation and fibrosis in vivo. }\end{array}$ \\
\hline & & $\begin{array}{l}\text { PEG hydrogel to deliver IL-10 for treatment of unilateral ureteral obstruction by reducing infiltration of inflammatory cells, } \\
\text { apoptosis and fibrosis in vivo. }\end{array}$ \\
\hline & & Chitosan hydrogel for 3D culture of ADSC and improving renal functions through reducing the production of ROS in vivo. \\
\hline \multirow{7}{*}{ Neuropathy } & \multirow{4}{*}{$\begin{array}{l}\text { Naturally- } \\
\text { derived } \\
\text { hydrogels for } \\
\text { treatment of } \\
\text { neuropathy }\end{array}$} & $\begin{array}{l}\text { Chitosan hydrogel to support the 3D culture of murine primary cortical neurons and the formation of neurite extensions upon growth } \\
\text { factor stimulation. }\end{array}$ \\
\hline & & $\begin{array}{l}\text { Chitosan/alginate hydrogel for 2D culture of murine neural stem cells and olfactory ensheathing cells upon stimulation with bFGF } \\
\text { and B27. }\end{array}$ \\
\hline & & $\begin{array}{l}\text { Silk fibroin hydrogel for the release of NT-3 to allow the growth of neurite extensions of chick embryo DGR under 2D cell culture } \\
\text { conditions. }\end{array}$ \\
\hline & & $\begin{array}{l}\text { Chitosan/alginate gel to favor neural differentiation of murine neural stem cells after stimulation with conditioned media under 3D } \\
\text { and 2D cell culture conditions. }\end{array}$ \\
\hline & \multirow{3}{*}{$\begin{array}{l}\begin{array}{l}\text { Synthetically- } \\
\text { derived }\end{array} \\
\text { hydrogels for } \\
\text { treatment of } \\
\text { neuropathy }\end{array}$} & $\begin{array}{l}\text { hSAF peptide gel functionalized with RGD to support the differentiation of murine embryonic neural stem cells into neural cells } \\
\text { under } 2 \mathrm{D} \text { cell culture conditions. }\end{array}$ \\
\hline & & RADA16 hydrogel functionalized with RGD and IKVAV within a PLLA conduct to repair nerve injury in vivo. \\
\hline & & $\begin{array}{l}\text { Heparin-F127 Pluronic hydrogel for encapsulation of bFGF and NGF and improving motor nerve functionality, axon regeneration } \\
\text { and remyelination in vivo. }\end{array}$ \\
\hline \multirow{4}{*}{ Retinopathy } & \multirow{4}{*}{$\begin{array}{l}\text { Synthetic and } \\
\text { hybrid gels for } \\
\text { treatment of } \\
\text { retinopathy }\end{array}$} & Silicone hydrogels (HEMA/MSC-MC12/APMA) to release Epalrestat into bovine corneas in situ under hyperglycemic conditions. \\
\hline & & Poly (NIPAAm-co-Dex-lactateHEMA) hydrogel for long-term insulin delivery and survival of retinal cells ex vivo and in vivo. \\
\hline & & $\begin{array}{l}\text { Hyaluronan/methylcellulose hydrogel for long-term controlled release IGF-1 in vitro and 3D culture of human retinal pigment } \\
\text { epithelium cells. }\end{array}$ \\
\hline & & Hyaluronan/methylcellulose hydrogel for 3D culture of murine retinal stem cells and their delivery into murine subretinal tissue. \\
\hline
\end{tabular}
Summary of advanced hydrogels to address nephropathy, neuropathy and retinopathy.

ADSCs = adipose tissue-derived stem cells, bFGF $=$ basic fibroblast growth factor, DGR $=$ dorsal root ganglion, IGF-1 $=$ insulin-like growth factor-1, IKVAV $=$ isoleucine, lysine, valine, alanine respectively, IL-10 = Interleukin 10, NGF = nerve growth factor, PEG $=$ polyethylene glycol, PLLA $=$ polylactic acid, PNIPAAm $=$ poly $(N-$ isopropylacrylamide), RADA = arginine, alanine, aspartic acid, alanine, respectively, RGD = arginine, glutamine, aspartica acid respectively, ROS = reactive oxygen species, TGF-betal $=$ transforming growth factor-beta $1,2 \mathrm{D}=$ two-dimensional, $3 \mathrm{D}=$ three-dimensional

This article is protected by copyright. All rights reserved. 
Table 4. Hydrogel-based products for treatment of hyperglycemia and diabetic foot ulcer.

\begin{tabular}{|c|c|c|c|c|c|}
\hline $\begin{array}{l}\text { Medical } \\
\text { condtion }\end{array}$ & Brand name & Company & Class & Composition and mechanism of action & Authorization \\
\hline \multirow{2}{*}{ Hyperglycemia } & $\begin{array}{l}\text { TransCon } \\
\text { Hydrogel Insulin }\end{array}$ & Sanofi & \multirow{2}{*}{$\begin{array}{l}\text { Anti-diabetic } \\
\text { hydrogel }\end{array}$} & $\begin{array}{l}\text { Insulin conjugated to branched PEG that autohydrolysis under } \\
\text { physiological conditions, providing sustained release of insulin. }\end{array}$ & $\begin{array}{l}\text { Not approved } \\
\text { (under trials) }\end{array}$ \\
\hline & $\begin{array}{l}\text { TransCon } \\
\text { Hydrogel GLP-1 }\end{array}$ & Sanofi & & $\begin{array}{l}\text { GLP-1 conjugated to branched PEG through autohydrolysis } \\
\text { responsive to } \mathrm{pH} \text { and temperature changes. }\end{array}$ & $\begin{array}{l}\text { Not approved } \\
\text { (under trials) }\end{array}$ \\
\hline \multirow{11}{*}{$\begin{array}{l}\text { Diabetic foot } \\
\text { ulcer }\end{array}$} & Apligraf® & $\begin{array}{l}\text { Organogenesis } \\
\text { Inc. }\end{array}$ & $\begin{array}{l}\text { Allogeneic } \\
\text { cellular skin } \\
\text { substitute }\end{array}$ & $\begin{array}{l}\text { Bilayered bioengineered skin substitute. The dermal part is a } \\
\text { collagen hydrogel for human fibroblasts } 3 \mathrm{D} \text { culture. }\end{array}$ & FDA approved. \\
\hline & Leucopatch $®$ & Reapplix. & $\begin{array}{l}\text { Autologous } \\
\text { cellular skin } \\
\text { substitute }\end{array}$ & $\begin{array}{l}\text { Three-layer patch produced from patient's blood: polymerized } \\
\text { fibrin hydrogel layer for moisture retention and platelets layer. }\end{array}$ & FDA approved. \\
\hline & Regranex® Gel & Smith \& Nephew. & \multirow{7}{*}{$\begin{array}{l}\text { Acellular } \\
\text { biologics }\end{array}$} & $\begin{array}{llll}\begin{array}{l}\text { Recombinant } \\
\text { carboxymethylcellulose hydrogel. }\end{array} & \text { becaplermin } & \text { in } & \text { sodium } \\
\end{array}$ & FDA approved. \\
\hline & Intrasite ${ }^{\circ} \mathrm{Gel}$ & Smith \& Nephew. & & $\begin{array}{l}\text { Carmellose polymer and propylene glycol re-hydrates necrotic } \\
\text { tissue, facilitating autolytic debridement. }\end{array}$ & Not approved \\
\hline & Purilon $®$ Gel & Coloplast. & & $\begin{array}{l}\text { Sodium carboxymethylcellulose and calcium alginate. Re- } \\
\text { hydrates necrotic tissue, facilitating autolytic debridement. }\end{array}$ & Not approved \\
\hline & Curasite ${ }^{\circledR}$ Gel & $\begin{array}{c}\text { Izun } \\
\text { Pharmaceuticals. }\end{array}$ & & Botanical extract. & Not approved \\
\hline & Dermagrid & MxBiodevices. & & $\begin{array}{l}\text { Denatured collagen and dextran. Hydration and nanofiber } \\
\text { scaffold. }\end{array}$ & $\begin{array}{l}\text { Not approved } \\
\text { (under trials) }\end{array}$ \\
\hline & Flaminal Forte ${ }^{\circledR}$ & Flen Pharma. & & $\begin{array}{l}\text { Alginate hydrogel loaded with glucose oxidase and } \\
\text { lactoperoxidase. Debrides the wound, reduces excessive protease } \\
\text { activity and manages moisture balance through hydration. }\end{array}$ & \multirow{4}{*}{ Not approved } \\
\hline & Saf-Gel® & ConvaTec & & Sodium alginate hydrogel. Manages moisture through hydration. & \\
\hline & Hyalogran $®$ dressing & $\begin{array}{c}\text { Anika } \\
\text { Therapeutics }\end{array}$ & \multirow[b]{2}{*}{$\begin{array}{l}\text { Acellular } \\
\text { hydrogel-based } \\
\text { dressing }\end{array}$} & $\begin{array}{l}\text { Dressing formed of a HA ester. Absorbs wound exudate and fuse } \\
\text { into the wound allowing for necrotic tissue removal. }\end{array}$ & \\
\hline & $\begin{array}{l}\text { SeaSorb Ag® } \\
\text { dressing }\end{array}$ & Coloplast & & $\begin{array}{l}\text { Calcium alginate, carboxymethyl cellulose and an ionic silver } \\
\text { complex. Manages moisture balance through hydration, } \\
\text { accompanied by anti-microbial effect through the sustained } \\
\text { release of silver ions in presence of wound exudate. }\end{array}$ & \\
\hline
\end{tabular}

This article is protected by copyright. All rights reserved. 


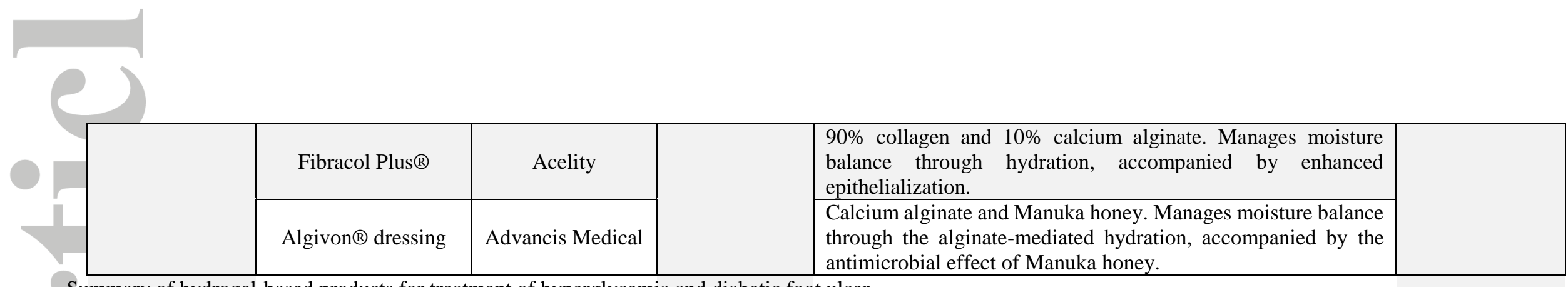

Summary of hydrogel-based products for treatment of hyperglycemia and diabetic foot ulcer.

$\mathrm{HA}=$ hyaluronic acid, GLP-1 = glucagon-like peptide-1, PDGF = platelet-derived growth factor, $\mathrm{PEG}=$ polyethylene glycol, $3 \mathrm{D}=$ three-dimensional.
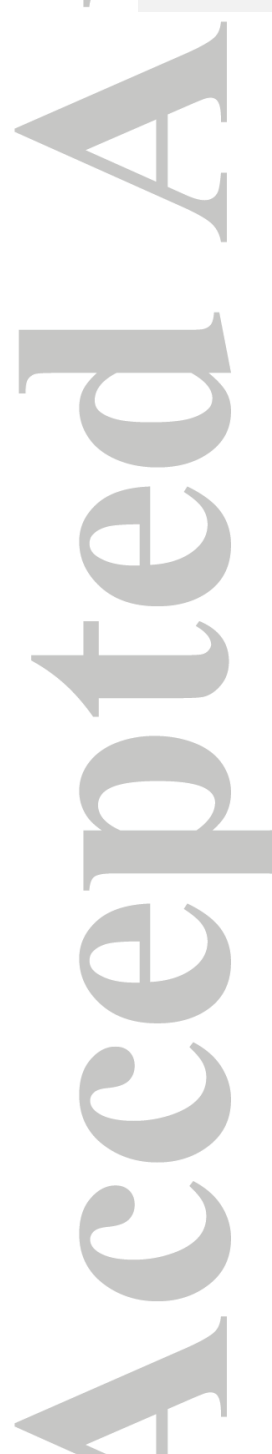